Natloñal Bureau o

Library, E. $\Omega 1$ nd-in. B'dg.

Reterence dook not to de

AUG $6 \quad 1971$ taken from the library.

BUILDING SCIENCE SERIES

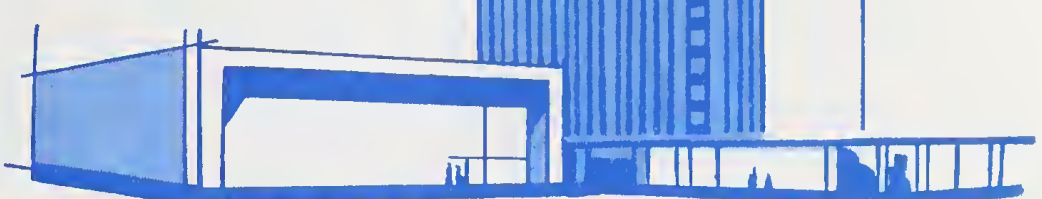

Causes of Variation

In Chemical Analyses

And Physical Tests

of Portland Cement

U.S. DEPARTMENT OF COMMERCE

National Bureau of Standards 


\section{Announcing - The Building Science Series}

The "Building Science Series" disseminates technical information developed at the Bureau on building materials, components, systems, and whole structures. The series presents research results, test methods, and performance criteria related to the structural and environmental functions and the durability and safety characteristics of building elements and systems.

These publications, similar in style and content to the NBS Building Materials and Structure Reports (1938-59), are directed toward the manufacturing, design, and construction segments of the building industry, standards organizations, officials responsible for building codes, and scientists and engineers concerned with the properties of building materials.

The material for this series originates principally in the Building Research Division of the NBS Institute for Applied Technology. Published or in preparation are:

BSS1. Building Research at the National Bureau of Standards. (In preparation.)

BSS2. Interrelations Between Cement and Concrete Properties: Part 1, Materials and Techniques, Water Requirements and Trace Elements. 35 cents.

BSS3. Doors as Barriers to Fire and Smoke. 15 cents.

BSS4. Weather Resistance of Porcelain Enamels: Effect of Exposure Site and Other Variables After Seven Years. 20 cents.

BSS5. Interrelations Between Cement and Concrete Properties: Part 2, Sulfate Expansion, Heat of Hydration, and Autoclave Expansion. 35 cents.

BSS6. Some Properties of the Calcium Aluminoferrite Hydrates. 20 cents.

BSS7. Organic Coatings - Properties, Selection, and Use. $\$ 2.50$.

BSS8. Interrelations Between Cement and Concrete Properties: Part 3, Compressive Strength of Mortars. 55 cents.

BSS9. Thermal-Shock Resistance for Built-up Membranes. 20 cents.

BSS10. Field Burnout Tests of Apartment Dwelling Units. 25 cents.

BSS11. Fire Resistance of Steel Deck Floor Assemblies. 25 cents.

BSS12. Performance of Square-Edged Orifices and Orifice-Target Combinations as Air Mixers. 15 cents.

BSS13. Shrinkage and Creep in Prestressed Concrete. 15 cents.

BSS14. Experimental Determination of Eccentricity of Floor Loads Applied to a Bearing Wall. 15 cents.

BSS15. Interrelations Between Cement and Concrete Properties: Part 4, Shrinkage of Hardened Portland Cement Pastes. (In preparation.)

BSS16. Techniques for the Survey and Evaluation of Live Floor Loads and Fire Loads in Modern Office Buildings. (In preparation.)

Send orders with remittance to: Superintendent of Documents. U.S. Government Printing Office,

Washington, D.C. 20402. Remittances from foreign countries should include an additional one-fourth of the price for postage.

[See mailing list announcement on last page.] 
UNITED STATES DEPARTMENT OF COMMERCE • Maurice H. Stans, Secretary

A. V. Astin, Director

\section{Causes of Variation in Chemical Analyses and Physical Tests of Portland Cement}

B. Leonard Bean and John R. Dise

Building Research Division Institute for Applied Technology

National Bureau of Standards

Washington, D.C. 20234

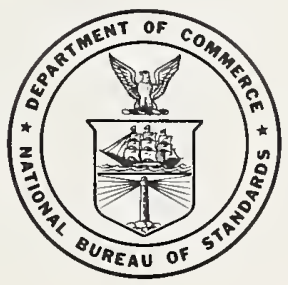

Building Science Series 17

Issued March 1969

(Supersedes NBS Monograph 28) 


\section{RELATED PUBLICATIONS}

NBS Monograph 28-Causes of Variation in Chemical Analyses and Physical Tests of Portland Cement -25 cents*

NBS Monograph 43-Chemistry of Cement Proceedings of the Fourth International Symposium-Washington 1960. Presented in two volumes. Volume I-\$6.50. Volume II $-\$ 6.25$. The two volumes at $\$ 12.75$ a set. (Originally issued September 1962, and reprinted February 1964.)

NBS Building Science Series 2 and 5 - Interrelations between Cement and Concrete Properties. Part $1-35^{\circ}$ cents. Section 1, Materials and Techniques. Section 2, Water Requirements of Portland Cement. Section 3, Occurrence of Minor and Trace Elements in Portland Cement. Part 2-35 cents. Section 4, Variables associated with expansion in the potential sulfate expansion test. Section 5 , Heat of hydration of portland cement. Section $6, V$ ariables associated with small autoclave expansion values of portland cements. Section 7, Compressive Strength of Test Mortars. Section 8, Compressive Strength of Steam-Cured Portland Cement Mortars. Part 3-55 cents.

* Order publications from Superintendent of Documents, Government Printing Office, Washington, D.C. 20402. (For foreign mailing, add one-fourth of the price of the publication.) 


\section{Preface}

Reference to this publication may help a cement testing laboratory engaged in comparative testing to identify and eliminate the causes of erroneous test results. The compilation should also be helpful to laboratories that consider it advisable to conduct general inspections of equipment and procedures at regular intervals. 


\section{Contents}

Page

Preface............. III

1. Introduction.............................. 1

Part I. Possible causes of error in cement analysis........................................

2. General precautions........................ 2.1. The weighing operation................

2.2. Ignition procedures..................

2.3. Desiccation..........................

2.4. Additional precautions................

Individual determinations.............

3. Silicon dioxide........................... 5

3.1. Causes of variations................. 5

4. Ammonium hydroxide group $\left(\mathrm{R}_{2} \mathrm{O}_{3}\right) \ldots \ldots 6$ 4.1. Causes of variations.................. 6

5. Total iron as ferric oxide................... 7

5.1. Causes of variations.................. 7

6. Aluminum oxide........................... 7

7. Calcium oxide............................ 7

7.1. Causes of variations.................. 7

8. Magnesium oxide........................ 8

8.1. Causes of variations.................. 8

9. Sulfur trioxide............................. 9

9.1. Causes of variations................. 9

9.1.1. Turbidimeter method ................ 9

9.1.2. Gravimetric method................ 9

10. Sulfide sulfur............................ 10

11. Loss on ignition............................. 10

11.1. Causes of variations................ 10

12. Sodium oxide and potassium oxide....... 10

12.1. Causes of variations................ 10

13. Phosphorus pentoxide..................... 11

14. Manganic oxide.............................. 11

14.1. Causes of variations................. 11

15. Insoluble residue ........................ 11

Concluding remarks..................... 11

Part II. Possible causes of variation in physical tests of portland cements................ 13

16. General considerations in the physical testing of cements........................ 13

16.1. Laboratory........................... 13

16.2. Treatment of samples............ 13

16.3. Mixing water...................... 13

16.4. Measurement of mixing water.... 13

16.5. Standard sands..................... 14

16.6. Weighings......................... 14

16.7. Timing device........................ 14

16.8. Oiling of molds.................... 14
16.9. Specimen storage facilities........ 14

16.10. Storage period for molded specimens..................... 14

16.11. Removal of specimens from molds........................... 15

16.12. Marking specimens............... 15

16.13. Trowels............................ 15

16.14. Rubber gloves..................... 15

16.15. Care and cleaning of apparatus... 15

17. The determination of fineness........... 15

17.1. Common causes of variations..... 15

17.2. The turbidimeter fineness test... 16

17.2.1. Causes of variations.............. 16

17.3. The air permeability fineness test............................... 18

17.3.1. Causes of variations.............. 18

18. Consistency............................. 19

18.1. Mechanical mixing of pastes and mortars........................ 19

18.1.1. Causes of variations............... 20

18.2. The normal consistency determination........................ 20

18.2.1. Causes of variations............... 21

18.3. The flow table test.............. 21

18.3.1. Causes of variations................ 21

19. The autoclave soundness test............. 22

19.1. Causes of variations................ 22

20. Time of setting.......................... 23

20.1. Common causes of variations..... 23

20.2. The Vicat time of setting test..... 24

20.2.1. Causes of variations............... 24

20.3. The Gillmore time of setting test............................ 24

20.3.1. Causes of variations............... 24

21. The heat of hydration test .............. 25

22. The false set test....................... 25

22.1. Causes of variations................ 25

23. Air content of mortar..................... 26

23.1. Causes of variations................. 26

24. Strength of mortars........................ 26

24.1. Common causes of variations..... 26

24.2. The compressive strength test... 27

24.2.1. Causes of variations............... 27

24.3. The tensile strength test......... 28

24.3.1. Causes of variations.............. 28

25. Closure................................... 29

26. References............................. 29 


\title{
Causes of Variation in Chemical Analyses and Physical Tests of Portland Cement
}

\author{
B. Leonard Bean and John R. Dise
}

\begin{abstract}
Variations in testing that could lead to the rejection of a material fully conforming to specification requirements, or the acceptance of a material with undesirable chemical or physical properties, are apparent in the results reported by laboratories participating in comparative tests of portland cements. Many of the causes for variation in chemical analyses and physical test results are listed in this discussion, and remedies for some of the more frequently encountered deficiences in apparatus and methods are suggested. Particular consideration is given to problems which do not seem to have been covered in sufficient detail in previous discussions of cement testing procedures. Literature references are given for additional information. This publication supersedes NBS Monograph 28.
\end{abstract}

Key Words: Portland cement; chemical analyses; physical tests.

\section{Introduction}

Many of the organizations engaged in the testing of portland cements have found it advantageous to use frequent interlaboratory tests on carefully prepared samples of the material to evaluate the performance of the laboratories involved. A report on a comprehensive effort of this kind was submitted to the American Society for Testing Materials at its 1959 Annual Meeting in Atlantic City, New Jersey [1]. ${ }^{1}$

All too frequently, variations in testing that could lead to the rejection of a portland cement fully conforming to specification requirements, or the acceptance of one with undesirable properties, are apparent in the results reported by the participants in these programs. This is due in large measure to the fact that many steps are involved in making the standard chemical analyses and physical tests, and that the results are sometimes greatly influenced by seemingly minor variations in equipment and procedures. Many of these influences have been taken into account in the preparation of the standard methods of test. However, it is not uncommon to find that inadequate attention has been given to certain important specification requirements because their significance is not fully understood, or that essential considerations are overlooked simply because they are not readily apparent. For these reasons it is believed that a discussion of the causes of variation, in which particular attention is given to matters not already covered in detail in current publications, might prove helpful to laboratories participating in comparative test programs such as the Cement Reference Sample Program of NBS.

${ }^{1}$ Figures in brackets indicate the literature references at the end of this paper. 



\title{
Part I. Possible Causes of Error in Cement Analysis
}

\author{
B. Leonard Bean*
}

\begin{abstract}
In the analysis of portland cement to determine compliance with specification requirements, the following constituents are usually reported (expressed generally as oxides, but it is not inferred that they are necessarily present in that form in cement): $\mathrm{SiO}_{2}, \mathrm{Fe}_{2} \mathrm{O}_{3}, \mathrm{Al}_{2} \mathrm{O}_{3}, \mathrm{CaO}, \mathrm{MgO}_{3} \mathrm{SO}_{3}$. Determinations of the loss on ignition and insoluble residue are also required. If specified by the purchaser or otherwise required by the purchase contract, determinations of sulfide sulfur, sodium oxide, potassium oxide, titanium dioxide, phosphorus pentoxide, manganic oxide, chloroform soluble organic substances, and free calcium oxide may also be required. The suggestion was made that this author compile information on analytical techniques, both from personal experience and from the literature, which might aid analysts in securing uniform and reliable results. The suggestions which follow, it is hoped, will benefit one who is seeking some means to bring his own results into line with the average values reported by all chemists taking part in a cooperative study.
\end{abstract}

Key Words: Portland cement; chemical analysis.

\section{General Precautions}

\subsection{The Weighing Operation}

The weights used in interlaboratory analyses should conform to Class S-1 requirements as commonly shown in equipment catalogs. The weights of $1 \mathrm{~g}$ and larger units should preferably be made of stainless steel or other corrosion and abrasion-resistant alloy not requiring protective coating. Weights which are used for regular work should frequently be checked against a reference set of standard weights which conform to Class $\mathrm{S}$ (or Class M) requirements. This reference set should contain weights from $50 \mathrm{~g}$ to $10 \mathrm{mg}$. Whenever a weight from a working set is known to have been dropped, it should be cleaned and its weight checked carefully against weights from a reference set before further use. When weights from a reference set are involved in an accident such as being dropped to the floor, the calibration of the weights involved in the accident must be considered to be in doubt. Such weights can be recalibrated and/or adjusted by the manufacturer, the local State's Weights and Measures officials, or an appropriate testing laboratory.

Balances are now sold with many added features to speed the weighing process: damping devices, notched beams to accommodate poises, chains, projected direct-reading scales, and sets of built-in weights. These can save weighing time. Tests in accordance with ASTM E 319-67 (Methods for Testing Balances) must be made occasionally to assure freedom from significant errors.

Electrostatic effects must be guarded against in all weighing operations. The moisture that may condense on a dry crucible on a balance pan, due to humid atmospheres, can be compensated to some extent by placing a tare crucible on the other balance pan; or by appropriate choice of weighing methods with a balance of the single-arm type with only one pan.

* Research Chemist, Materials Division, Bureau of Public Roads, Federal Highway ddministration, U.S. Department of Transportation, W ashington, D.C. 20591.
It may be necessary to return a balance or set of weights to the manufacturer for adjustment or repair. However, local service by manufacturers' recommended service agencies will correct most troubles. In some cases annual service contracts may be desirable.

\subsection{Ignition Procedures}

Where platinum crucibles are used, they should, in general, be made of pure platinum, that is, not intentionally alloyed with other metals. At the temperatures of 1,100 and $1,200{ }^{\circ} \mathrm{C}$ used for certain ignitions in cement analysis, other alloying metals are liable to volatize slowly and vitiate the results obtained. Such alloyed crucibles or lids are sold and used for some purposes because they are stiffer and do not deform as readily as pure platinum. Some manufacturers have equipped pure platinum crucibles with alloyed lids to obviate sticking of crucible and lid. Such practice may be permissible at lower temperatures than those used in cement analysis. Any empty crucible and lid which consistently loses more than $0.2 \mathrm{mg}$ per hr at $1,200{ }^{\circ} \mathrm{C}$ should be suspected [2]. Use of an empty alloyed crucible and correction for the loss it sustains applied to the crucibles containing precipitates is liable to lead to erroneous results. The alloying metal covered with precipitate will probably not volatize at the same rate as in the empty crucible. Pure platinum crucibles may be purchased which have reinforced rims and bottoms. This minimizes deformation without the use of other alloyed metals.

The beginning of the ignition of a precipitate contained in a wet filter paper should be made at a rate slow enough so that no spattering, popping, or flaming occurs. After the moisture is expelled the paper should be "smoked off." Then, when all danger of flaming is past, the crucible may be placed in a muffle furnace which is at the proper temperature for final ignition.

Some check on the temperatures of the muffle furnaces is advisable from time to time. Con- 
tamination of thermocouples may occur resulting in erroneous temperature readings. A standard thermocouple and portable potentiometer may be used to check the accuracy of the thermocouples and temperature-indicating devices ordinarily used. The National Bureau of Standard issues a copper melting-point standard, No. 45c, which melts at $1,083.3^{\circ} \mathrm{C}$. Use of pyrometric cones may be helpful in checking temperatures [3].

E. T. Carlson [4] recommends a modification of Roberts' technique [5] utilizing the melting point of potassium sulfate $\left(1,069.1^{\circ} \mathrm{C}\right)$ as a check on muffle temperatures. Carlson breaks up the $\mathrm{K}_{2} \mathrm{SO}_{4}$ with a mortar and pestle and places about a gram in each of several covered platinum crucibles. These are placed at several points in the furnace with the indicated temperature somewhat below $1,069^{\circ} \mathrm{C}$. They are removed and inspected at about 15 min intervals. The indicated temperature of the muffle is raised by $10{ }^{\circ} \mathrm{C}$ intervals. In this manner the temperature of the various zones in the furnace can be estimated. Almost invariably the $\mathrm{K}_{2} \mathrm{SO}_{4}$ in the back of the furnace will melt first and that at the front last. One must not be confused by an inversion that takes place in $\mathrm{K}_{2} \mathrm{SO}_{4}$ at about $583{ }^{\circ} \mathrm{C}$, but without melting. The $\mathrm{K}_{2} \mathrm{SO}_{4}$ is first crushed to avoid the spattering that takes place on inversion.

When igniting precipitates in a number of crucibles, six, for example, it is well to reverse the order of the crucibles when about half the ignition period has elapsed. Thus crucible No. 1 which may at first have been at the front of the furnace in the coolest position will spend the remainder of the time in the back of the furnace which is usually the hottest zone. (In some furnaces, the middle portion may be hottest.) It should be borne in mind also that the temperature shown by the indicating device is the temperature of the end of the thermocouple. If the thermocouple is covered by a protective tube, as is usually the case, the temperature of any one crucible on or near the floor of the furnace will probably differ somewhat from the thermocouple temperature. The position of the thermocouple is important. It should be near the middle of the heated zone. If it is accidentally bumped while placing crucibles in the furnace, it may be so misplaced that it no longer indicates the average furnace temperature. The thermocouple position should be checked every time the muffle furnace is used.

\subsection{Desiccation}

No absolute rules can be given for desiccation. The time and technique which will give satisfactory desiccation while the crucibles are cooling to room temperature so that they can be weighed, may be a function of many factors: (1) Size of the desiccator, (2) the number of crucibles, their weight, and the weight of the contents, (3) the character or composition of the contents, (4) the material of which the desiccator is constructed, (5) the temperature and relative humidity in the room (6) the desiccant used, and (7) the degree to which the lid fits the desiccator. An excellent discussion of the subject is given by Hillebrand, Lundell, Bright, and Hoffman [6]. In general, sulfuric acid or anhydrous magnesium perchlorate are the preferred desiccants for cement analysis. Either is satisfactory in glass desiccators; obviously, sulfuric acid should not be used in an aluminum desiccator. The lid should be ground to fit the desiccator on which it is used. Generally no difficulty is encountered in purchasing glass desiccators whose lids fit properly. A wellconstructed aluminum desiccator has the advantage over glass of speeding the cooling of ignited precipitates, but in the writer's experience, the lids rarely fit properly and require regrinding before use. It has been claimed that the cost of such grinding by the manufacturer would be prohibitive. Ordinary silicone stop cock grease (not High.Vac) is a good sealing and lubricating material for aluminum desiccators if the lids fit. Petrolatum is satisfactory for glass desiccators.

When the lid of a desiccator fits and is lubricated properly, air will be heard to rush in when the cooling period (usually 30 to $60 \mathrm{~min}$ ) is over and the lid is opened slightly by cautiously sliding or by opening a valve, if the desiccator is so equipped. If this sound is not heard one is always uncertain as to how much moisture-laden room air may have entered the desiccator during the cooling period. Care must be exercised to avoid blowing precipitates out of the crucibles by this inrushing air. If a desiccator has been found not to have been kept tightly closed overnight, it is good practice to recharge with fresh desiccant.

Hot crucibles should never be placed in a desiccator at quitting time and then weighed in the morning. Such weights will seldom agree with those obtained after the usual cooling period. Weighings made just prior to quitting time should be viewed with suspicion if there has been any tendency to shorten the usual desiccating period in favor of leaving at a given hour. Crucibles and contents which appear to gain weight on the balance during weighing may have been left in the desiccator for too short a period. Slightly warm crucibles cause convection currents in the balance and affect it in other ways which generally result in a weight which is too low and somewhat unstable during the weighing period. This latter phenomenon may be superimposed on the uncertainty involved in weighing hydroscopic materials which have been properly cooled for a sufficient length of time in a good desiccator.

Ignited silica, ammonium hydroxide group $\left(\mathrm{R}_{2} \mathrm{O}_{3}\right)$, and calcium oxide should be treated as hydroscopic materials, or potentially so, and kept tightly covered in the crucible during desiccation and weighing. Calcium oxide should be desiccated over mag- 
nesium perchlorate or preferably, phosphorus pentoxide and weighed as rapidly as possible.

It is not easy to know when a desiccator should be recharged with fresh desiccant. G. Boehm [6, p. 33, note 22] describes a technique ${ }^{2}$ for checking the effectiveness of sulfuric acid as a drying agent, by using acid containing $18 \mathrm{~g}$ of $\mathrm{BaSO}_{4}$ dissolved in each liter. Some analysts have found it useful to mix a few pieces of indicating Drierite with magnesium perchlorate in a desiccator; when the blue color changes to pink the desiccant should be discarded. In fact, it probably should have been discarded prior to that. Most laboratories do not have the vacuum equipment required to reactivate magnesium perchlorate and prefer to discard the used material and recharge the desiccator with fresh material.

\subsection{Additional Precautions}

Filter paper should be visually inspected before folding and, of course, discarded if evidence of a weak spot or a hole is detected.

A piece of glass broken from a wash bottle tip is an occasional cause of high results.

Failure to decompose the sample of cemcnt completely in the initial hydrochloric acid treatment can lead to erroneous results for almost all subsequent determinations.

Silicone stopcock grease is not recommended for use in burettes. It may tend partially to waterproof the inner surface of the burette. Silicone grease can be removed from a burette by use of fuming sulfuric acid. Extreme caution must be exercised in using fuming sulfuric to avoid injury.

\section{Individual Determinations}

Many of the statements which follow are intended to apply to comparative analyses in which, presumably, the utmost in accuracy is sought. Less rigorous techniques may be satisfactory for routine analyses, where conformance to specification requirements is not in doubt.

\section{Silicon Dioxide}

This determination is based on either of two methods:

Referee. A double evaporation is made of the hydrochloric acid solution of the cement to dryness to convert $\mathrm{SiO}_{2}$ to the insoluble form. The solution is filtered and the insoluble siliceous residue is volatilized by hydrofluoric acid and the loss of weight is reported as pure $\mathrm{SiO}_{2}$.

Optional. In this method silicon dioxide is determined gravimetrically as in the referee method except that ammonium chloride is added and the solution is not evaporated to dryness. The method was developed for the analysis of portland cement and is not recommended for other types of hydraulic cements. ${ }^{3}$

\subsection{Causes of Variations}

High Results. For the determination of silica, ignition temperature of $1,200{ }^{\circ} \mathrm{C}$ for at least $1 \mathrm{hr}$ is recommended, with subsequent heating periods of $30 \mathrm{~min}$ at the same temperature until constant weight within $0.2 \mathrm{mg}$ has been established [8, also 6, p. 679].

Recovery of residual silica from the ignited ammonium hydroxide precipitate together with a

2 ". . . no precipitate will form in sulfuric acid containing $18 \mathrm{~g}$ of dissolved barium sulfate per liter until enough water has been taken up to reduce the concentration of acid to about 93 percent. Between 93 and 84 percent, needlelike crystals of $\mathrm{BaSO}_{4} \cdot 2 \mathrm{H}_{2} \mathrm{SO}_{4} \cdot \mathrm{H}_{2} \mathrm{O}$ separate freely. On further dilution by absorbed water, the needlelike crystals change to fine crystals of $\mathrm{BaSO}_{4}$, at which point the acid is no longer effective as a drying agest."

${ }^{3}$ The brief summaries of methods in this discussion contain much of the same material that is in the summaries given in ASTM C114-67 [7]. correction for the silica recovered from a reagent blank can lead to high results. This is discussed on page 682 of [6], where the importance is stressed of adding as much iron and alumina to the reagent blank as is contained in the sample being analyzed. This is time-consuming and makes necessary the use of two blanks, if silica is to be recovered: one containing nothing but reagents in order to correct the $\mathrm{R}_{2} \mathrm{O}_{3}$ for filter paper ash; the other with added iron and alumina to carry down silica from the reagents and glassware. At the present time, neither ASTM [7, pp. 97-99] nor Federal [8, Method 1101, pars. 3.1.1 and 3.1.2] methods require recovery of silica from $\mathrm{R}_{2} \mathrm{O}_{3}$ because many chemists believe the amount involved is likely to be almost insignificant, the probable errors of recovery high, and the time required excessive. The same reasoning may not be valid concerning the effect on alumina values obtained if no correction is made for residual silica in $\mathrm{R}_{2} \mathrm{O}_{3}$.

Low Results. In careful work, the $\mathrm{HF}$ residue can generally be kept below $1 \mathrm{mg}$ in cement analysis. If the referee (double dehydration) method is used this residue should seldom be more than half a milligram. Whenever the $\mathrm{HF}$ residue is much higher than these values, uncertainty in results for silica exists, usually tending to give low silica values. (Subsequent determinations of other constituents may also be affected.) Impurities may be weighed as chlorides during the ignition of the crude silica and as sulfates or oxides after treatment with $\mathrm{HF}$ and $\mathrm{H}_{2} \mathrm{SO}_{4}$. The error can be minimized by following the usual dilute $\mathrm{HCl}(1: 99)$ and water washings 
of the precipitated silica with one or two washings with dilute $\mathrm{H}_{2} \mathrm{SO}_{4}(1: 4)$ or by moistening the combined papers containing the silica with a few drops of dilute sulfuric acid before drying and igniting [9, also 6, p. 863]. Thorough washing of silica to remove contaminants is the best insurance against high $\mathrm{HF}$ residues. The higher the $\mathrm{HF}$ residue the more error can be introduced if the contaminants are not present in the same form before and after treatment with $\mathrm{HF}$ and $\mathrm{H}_{2} \mathrm{SO}_{4}[6$, p. 681]. Special precautions need to be taken in washing when the optional ammonium-chloride method of silica separation is used. The bulk of the gelatinous silicic acid should be transferred to the funnel without dilution with water and the small volume of concentrated acid solution allowed to drain through. Thorough washing with hot $\mathrm{HCl}(1: 99)$ and then hot water follow. It is useful to tear off small pieces of filter paper and use them together with a rubber policeman to scrub the inside of the beaker thoroughly in order to remove all adhering silica. This use of filter paper should be delayed until no more ferric chloride color can be seen. If the scraps of filter paper are added to the funnel too soon, their presence impedes the washing procedure and causes high $\mathrm{HF}$ residue.

Where use of a steam bath is recommended for dehydration of silica, by either the double-dehydration or the ammonium chloride method, incomplete decomposition of the sample may occur if the water in the steam bath is not hot enough. The method of heating the steam bath should be so regulated that the water in the steam bath is maintained at a rolling boil. If the temperature of the water is below boiling, some silica may escape dehydration, causing low values to be obtained for silica, and high values for alumina, calcium oxide, and possibly magnesium oxide.

Low results for silica can be caused by baking the second dehydration at temperatures over $110^{\circ} \mathrm{C}$ or for longer than $1 \mathrm{hr}$. Such treatment can cause recombination of silica and magnesia, resulting in formation of an acid soluble silicate [6, p. 678].

\section{Ammonium Hydroxide Group $\left(\mathbb{R}_{2} \mathbf{O}_{3}\right)$}

In this method aluminum, iron, titanium, and phosphorus are precipitated from the filtrate, after $\mathrm{SiO}_{2}$ removal, by means of ammonium hydroxide. With care, little if any manganese will be precipitated. The precipitate is ignited and weighed as the oxides.

\subsection{Causes of Variations}

High Results. In the determination of the ammonium hydroxide group ignition of $\mathrm{R}_{2} \mathrm{O}_{3}$ at 1,100 ${ }^{\circ} \mathrm{C}$ for $1 \mathrm{hr}$ is recommended, followed by subsequent 30-min ignition periods until constancy of weight within $0.2 \mathrm{mg}$ is indicated.

If 10 to $15 \mathrm{ml}$ of $\mathrm{HCl}$ is not present before neutralization with $\mathrm{NH}_{4} \mathrm{OH}$, coprecipitation of some magnesium hydroxide with the $\mathrm{R}_{2} \mathrm{O}_{3}$ may occur. The presence of that quantity of $\mathrm{HCl}$ insures the formation of a sufficient amount of $\mathrm{NH}_{4} \mathrm{Cl}$ so that the ionization of $\mathrm{NH}_{4} \mathrm{OH}$ is depressed to a point where insufficient hydroxyl ion is present to exceed the solubility product of $\mathrm{Mg}(\mathrm{OH})_{2}$. Ammonium chloride also tends to keep magnesium in solution by formation of an ammonia complex, assists in buffering the solution, and aids in coagulation of the precipitate.

Use of ammonium hydroxide which contains carbon dioxide can cause coprecipitation of calcium and magnesium carbonates. Reagent ammonium hydroxide bottles should be kept stoppered to prevent contamination. Digestion of the ammoniacal solution and precipitate should not be prolonged beyond $10 \mathrm{~min}$. Otherwise $\mathrm{CO}_{2}$ may be absorbed from the air.
The results for $\mathrm{R}_{2} \mathrm{O}_{3}$ may be affected by the completeness of recovery of silica in the previous step. Any silica which has escaped the double dehydration or ammonium-chloride separation will cause high results for $\mathrm{R}_{2} \mathrm{O}_{3}$ unless a careful recovery of residual silica is made. This would then cause high results to be reported for aluminum oxide.

In careful analyses, all residual silica recovered from the $\mathrm{R}_{2} \mathrm{O}_{3}$ (whether from the cement, the reagents, or the glassware) should be subtracted from the $\mathrm{R}_{2} \mathrm{O}_{3}$ weight. It is certainly not $\mathrm{Al}_{2} \mathrm{O}_{3}$. For this purpose, the residual silica should not be corrected for the residual silica found in the blank to which iron and alumina had been added to sweep it down. In addition another correction should be made to the $\mathrm{R}_{2} \mathrm{O}_{3}$ weight, by subtracting the reagent blank, to correct for the impurities in the reagents (other than silica) and for the filter paper ash. This blank will generally amount to about $0.5 \mathrm{mg}$. Thus the total correction to be subtracted may be on the order of $1 . \mathrm{mg}$, the equivalent of 0.2 percent $\mathrm{Al}_{2} \mathrm{O}_{3}$. This may cause a significant difference in the calculated tricalcium aluminate content.

Low Results. Failure to neutralize with ammonia to the exact end point will cause low results. Stopping short of the methyl-red end point will leave some hydroxides unprecipitated. Going past the end point of methyl red by more than the one drop of 1:1 $\mathrm{NH}_{4} \mathrm{OH}$ prescribed, will redissolve alumina and cause low results. The presence of any iron in the ferrous condition will cause results to be low because ferrous hydroxide is not quantitatively precipitated at this $\mathrm{pH}$. Whenever ferrous iron is suspected, such as by a blackened precipi- 
tate, redissolve with hydrochloric acid, add four or five drops of concentrated nitric acid, and boil for a few minutes to oxidize all the iron. Then precipitate with $\mathrm{NH}_{4} \mathrm{OH}$ as before. It may be necessary to add more methyl-red indicator from time to time because of the effect of the nitric acid on the indicator.

In the event the first precipitation of $\mathrm{R}_{2} \mathrm{O}_{3}$ has been completed at the end of the working day, the filter paper together with its precipitate should not be treated with acid, pulped up, and allowed to stand overnight in this condition. It may even be better not to do this over a lunch hour. In a strongly acidic environment organic matter from the filter paper pulp tends to complex some of the aluminum and prevent completeness of precipitation on subsequent treatment with $\mathrm{NH}_{4} \mathrm{OH}[6$, pp. 66 and 98]. In this respect filter paper may act a little like tartaric or citric acid. Use of filter paper for this separation which is less retentive than Whatman \#40 is not recommended because some $\mathrm{Fe}(\mathrm{OH})_{3}$ might pass through.

\section{Total Iron as Ferric Oxide}

In this method, the $\mathrm{Fe}_{2} \mathrm{O}_{3}$ content of the cement is determined on a separate portion of the cement by reducing the iron to the ferrous state with stannous chloride $\left(\mathrm{SnCl}_{2}\right)$ and titrating with a standard solution of potassium dichromate $\left(\mathrm{K}_{2} \mathrm{Cr}_{2} \mathrm{O}_{7}\right)$. This determination is not affected by any titanium or vanadium that may be present in the cement.

\subsection{Causes of Variation}

In the determination of iron, the reduction process with stannous chloride is critical. If less than the required amount is added, results will be low. An excess of one drop after the yellow color of ferric ions disappears, will give satisfactory results provided the specified concentration of stannous chloride is used. This solution has a tendency to become more concentrated on standing in the presence of metallic tin. After cooling to room temperature and adding the mercuric chloride solution, a small amount of white silky precipitate should be in evidence. If none appears, insufficient stannous chloride was used and the determination should be repeated. The presence of much mercurous chloride is also objectionable because it may become oxidized. If the precipitate is gray, it indicates the presence of finely divided elemental mercury because too much stannous chloride had been used. In the latter event, also repeat the determination because the results will be high [9, pp. 573 and 580].

After reduction with stannous chloride, the solution should be cooled in a cool water bath and the remainder of the determination completed immediately thereafter. The reduced solution should not be allowed to stand overnight before titrating; air oxidation could cause low results.

\section{Aluminum Oxide}

Alumina is not actually determined in cement but is calculated by difference. The ammonium hydroxide precipitate in cement is assumed to consist of $\mathrm{Al}_{2} \mathrm{O}_{3}, \mathrm{Fe}_{2} \mathrm{O}_{3}, \mathrm{TiO}_{2}, \mathrm{P}_{2} \mathrm{O}_{5}$, and residual $\mathrm{SiO}_{2}$, together with possible traces of $\mathrm{ZrO}_{2}, \mathrm{~V}_{2} \mathrm{O}_{3}$, and $\mathrm{Cr}_{2} \mathrm{O}_{3}$. If, as is usually done, only the percentage of $\mathrm{Fe}_{2} \mathrm{O}_{3}$ is subtracted in the calculation, the results for $\mathrm{Al}_{2} \mathrm{O}_{3}$ will always be expected to be high by the amount of the other undetermined oxides. Any error in the $\mathrm{R}_{2} \mathrm{O}_{3}$ or $\mathrm{Fe}_{2} \mathrm{O}_{3}$ determinations will cause corresponding errors in the $\mathrm{Al}_{2} \mathrm{O}_{3}$ percentage reported. Note the suggestions given in the two preceding sections.

\section{Calcium Oxide}

This determination is based on either of two methods:

Referee, Gravimetric. Manganese is removed from the filtrate after the determination of the ammonium hydroxide group. Calcium is then doubly precipitated as the oxalate. The precipitate is converted to $\mathrm{CaO}$ by ignition and weighed.

Optional. The calcium oxide $(\mathrm{CaO})$ is determined volumetrically. After removal of silicon dioxide and the ammonium hydroxide group, the calcium is precipitated only once as the oxalate. After filtering, the oxalate is redissolved and titrated with potassium permanganate $\left(\mathrm{KMnO}_{4}\right)$.

\subsection{Causes of Variations}

High Results. In the determination of calcium oxide high results can be caused by failure to remove manganese, or to separate iron or alumina completely. When the optional method is used, the results obtained may be either high or low depending on the degree of washing with hot water. The suggestion in the specification method to use about $75 \mathrm{ml}$ of hot water in washing will generally be satisfactory. However, variations in size of wash bottle tips, lung power of individual chemists, and the degree to which the precipitated calcium oxalate 
is churned up during washing, will cause variations in the result. It is suggested that each analyst occasionally analyze a sample of an NBS standard sample of cement or a comparative sample whose composition has been established and vary his operations throughout the analysis, particularly his washing technique, until he is able to get $\mathrm{CaO}$ values close to the certificate value for that cement. If the final titration in the presence of the added filter paper is prolonged unduly some of the paper will be oxidized. The one-hour standing period for precipitation of the oxalate is critical and should not be prolonged lest coprecipitation of magnesium result.

It is difficult to ignite $\mathrm{CaO}$ to constant weight for the referee determination. Ignition at $1200{ }^{\circ} \mathrm{C}$ for at least $1 \mathrm{hr}$ is recommended, followed by heating at the same temperature for $30-$ min periods until constancy of weight within $0.2 \mathrm{mg}$ is indicated. The crucibles should have well fitting covers. Magnesium perchlorate is preferable to sulfuric acid for desiccating $\mathrm{CaO}$. Phosphorus pentoxide is definitely superior to either. The second weighing of $\mathrm{CaO}$ should be made in reverse order from the first weighing to detect any errors due to standing in a desiccator already opened. It is especially necessary to rotate the crucibles in the furnace for the CaO ignition.

Low Results. The presence of $\mathrm{CO}_{2}$ during the precipitation of the ammonium hydroxide group can cause some of the calcium to precipitate there instead of later as the oxalate. This was discussed more fully under the $\mathrm{R}_{2} \mathrm{O}_{3}$ precipitation. Failure to wash the $\mathrm{R}_{2} \mathrm{O}_{3}$ precipitate adequately may leave calcium absorbed on the gelatinous precipitate.

\section{Magnesium Oxide}

This determination is based on one of three methods.

Referee. Magnesium is doubly precipitated as magnesium ammonium phosphate from the filtrate after removal of calcium. The precipitate is ignited and weighed as magnesium pyrophosphate $\left(\mathrm{Mg}_{2} \mathrm{P}_{2} \mathrm{O}_{7}\right)$. The $\mathrm{MgO}$ equivalent is then calculated.

Optional Method A. Magnesium is precipitated only once as magnesium ammonium phosphate from the filtrate after removal of $\mathrm{CaO}$. The precipitate is ignited to $\mathrm{Mg}_{2} \mathrm{P}_{2} \mathrm{O}_{7}$ and weighed.

Optional Method B. This method may be used on the filtrate after removal of $\mathrm{CaO}$ or when the determinations of silicon dioxide $\left(\mathrm{SiO}_{2}\right)$, aluminum oxide $\left(\mathrm{Al}_{2} \mathrm{O}_{3}\right)$, ferric oxide $\left(\mathrm{Fe}_{2} \mathrm{O}_{3}\right)$, and calcium oxide $(\mathrm{CaO})$ are omitted. It is a volumetric procedure based on the precipitation of magnesium oxyquinolate (either in the absence or presence of calcium oxalate), filtration, and subsequent bromination with standard potassium bromate-potassium bromide solution and back titration of the excess with standard sodium thiosulfate $\left(\mathrm{Na}_{2} \mathrm{~S}_{2} \mathrm{O}_{3}\right)$ solution.

\subsection{Causes of Variations}

There are many precautions to be heeded in order to obtain correct results for the gravimetric determination of magnesium. The subject is covered thoroughly in authoritative discussions by Hoffman and Lundell [10], Kolthoff and Sandell [9, p. 352-62], and Hillebrand, Lundell, Bright, and Hoffman [6, p. 636-40]. It is impossible in a paper of this type to list more than a few precautions to be observed in the determination of magnesium by either the phosphate or oxyquinolate method.

High Results. If manganese has not been removed-and it is not mandatory-high values for magnesium may be obtained by the oxyquinolate (optional) method.

Use of filter paper that is too coarse for filtration of $\mathrm{R}_{2} \mathrm{O}_{3}$ may allow iron to run through and increase the subsequent $\mathrm{MgO}$ values. A green precipitate of what is supposed to be magnesium oxyquinolate is evidence of contamination by iron. This may also be caused by failure to keep all the iron in the ferric state during its precipitation and washing. The magnesium oxyquinolate precipitate should be yellow.

Berman found [11] that this method gave high results even after manganese removal in the case of cements containing over 2 percent $\mathrm{MgO}$.

When the phosphate (referee) method is used, any mechanical loss of calcium by creeping over or passing through the filter paper, will produce high results for magnesium because of coprecipitation of calcium phosphate.

If the ignition of magnesium ammonium phosphate in the presence of filter paper is carried out too rapidly, incorrect results, either high or low, may be obtained. The carbon may become partially fireproofed, rendering it impossible to burn it out $[6$, p. 637]. Or, the pyrophosphate may be slowly reduced and phosphorus volatilized. This latter action can ruin a platinum crucible. It is probably safer to ignite such precipitates in porcelain. The final ignition temperature should be $1,100{ }^{\circ} \mathrm{C}$. At $1,200{ }^{\circ} \mathrm{C}$, as permitted in some specification meth. ods, the pyrophosphate slowly loses weight $[9$, p. 359].

Low Results. Absence of sufficient $\mathrm{NH}_{4} \mathrm{Cl}$ during the $\mathrm{R}_{2} \mathrm{O}_{3}$ precipitation will cause some of the magnesium to precipitate there and subsequent values for $\mathrm{MgO}$ will be low.

During the calcium precipitation, if the oxalate is added to an ammoniacal solution, or if the solution and precipitate are boiled, some coprecipitation of magnesium will result [9, pp. 347-8]. Older specification methods recommend such procedure and some laboratories may still be using this technique, causing low magnesium results. 
Berman [11] reported low results for $\mathrm{MgO}$ by the optional oxyquinolate method at levels less than 1 percent $\mathrm{MgO}$.

In the phosphate (referee) method, supersaturated solutions of magnesium ammonium phosphate sometimes prevent complete precipitation in the case of low magnesia contents. This can be remedied by longer standing before filtration. It is generally advisable not to discard the filtrate from the phosphate separation for at least one day so that in the event postprecipitation does occur. the additional precipitate may be filtered off and added to the main precipitate. The blank should be treated in the same manner.

The amounts of ammonium oxalate called for in the specification methods for precipitation of calcium, generally do not leave enough excess to interfere with the magnesium determination according to Kolthoff and Sandell [9, p. 360]. In a few instances, in the author's experience, removal of oxalate and ammonium salts by evaporation with $75 \mathrm{ml}$ of nitric acid [6, p. 133] and [9, p. 370] has increased the amount of magnesium ammonium phosphate that could be precipitated from certain cements. For very careful work, the additional time consumed may be warranted.

\section{Sulfur Trioxide}

This determination is based on either of two methods:

Referee, Gravimetric. Sulfate is precipitated from an acid solution of the cement with barium chloride $\left(\mathrm{BaCl}_{2}\right)$. The precipitate is ignited and weighed as barium sulfate $\left(\mathrm{BaSO}_{4}\right)$ and the $\mathrm{SO}_{3}$ equivalent is calculated.

Optional, Turbidimetric. A rapid determination of sulfur trioxide content is made by means of a Wagner turbidimeter. The $\mathrm{SO}_{3}$ content of the sample under test is read from a calibration curve established with a cement of known $\mathrm{SO}_{3}$ content. Correct results depend upon a strict adherence to the specified conditions, times and temperatures.

\subsection{Causes of Variations}

\subsubsection{Turbidimeter Method}

When the optional, turbidimetric. method is used for the determination of sulfur trioxide, it is recommended that the operator study Rudy's paper [12] upon which the specification method was based. It contains many excellent suggestions and precautions to be observed: necessity for close control of temperature, changes of variables which require preparation of a new calibration curve, and necessity for maintaining fairly uniform $\mathrm{BaCl}_{2} \cdot 2 \mathrm{H}_{2} \mathrm{O}$ crystal size. In connection with the latter point, a further precaution might be in order. It is usual to separate a rather large supply of the $\mathrm{BaCl}_{2} \cdot 2 \mathrm{H}_{2} \mathrm{O}$ that will pass a No. 40 sieve and be retained on a No. 80 sieve, because a new calibration curve must be prepared every time a new batch is sieved. If, however, the operator should fall into the habit of shaking the bottle before taking out each scoop of crystals in the mistaken idea that mixing is desirable, he will actually change the crystal size by such shaking and obtain incorrect results. If four or five months have elapsed since the supply of crystals was sieved, it is advisable to resieve the $\mathrm{BaCl}_{2} \cdot 2 \mathrm{H}_{2} \mathrm{O}$ and prepare a new calibration curve anyway. The crystal size may have changed just by standing.

Molded glass sedimentation tanks should be used for $\mathrm{SO}_{3}$ determinations because hydrochloric acid solutions are liable to dissolve the material used to hold the glass together in forming the other type of tank.

Many of the suggestions given under 17.2 in Part II of this Monograph will be helpful in maintaining the turbidimeter in proper operating condition.

\subsubsection{Gravimetric Method}

From a study of the discussions on the determination of sulfur as barium sulfate in well-known textbooks such as those by Kolthoff and Sandell [9, pp. 322-335] and Hillebrand, Lundell, Bright, and Hoffman [6, pp. 711-722]. one almost reaches the conclusion that it should be impossible to obtain the correct result by precipitating $\mathrm{BaSO}_{4}$ in the presence of all the constituents of portland cement. Evidently, the reasonably good results generally obtained are because compensating errors just about balance each other. It will be noted in the certificate of analysis of NBS Standard Sample 177 that J. R. Spann, of our NBS laboratory, reported a value of 1.59 percent $\mathrm{SO}_{3}$ found in that cement. His method of determination included reduction of iron with hydroxylamine, addition of $\mathrm{BaCl}_{2}$ solution rapidly and treatment of the ignited $\mathrm{BaSO}_{4}$ with $\mathrm{HF}$ to remove silica $[9$, pp. 329, $330,332]$. In comparison with this value of 1.59 percent by a refined method, Spann obtained values of 1.56 percent and 1.63 percent $\mathrm{SO}_{3}$ for the same cement by the ASTM and Federal referee specification method.

Failure to wash out all the occluded $\mathrm{BaCl}_{2}$, or to burn off all the carbon of the filter paper, are probably the two most common causes of high results.

A digestion time much shorter than 12 hr generally leads to low results. After filtration, the precipitated $\mathrm{BaSO}_{4}$ should be washed thoroughly with hot water, as stated in the specification method. The temptation to use dilute $\mathrm{HCl}$ solution for washing in order to remove iron stains must be avoided. Any $\mathrm{Fe}_{2}\left(\mathrm{SO}_{4}\right)_{3}$ present already has a lower molecular 
weight than its equivalent amount of $\mathrm{BaSO}_{4}$ and will probably lose its $\mathrm{SO}_{3}$ during ignition. Washing out the $\mathrm{Fe}_{2}\left(\mathrm{SO}_{4}\right)_{3}$ with acid will make the results still lower. The silica occluded possibly compen. sates for the lower weight caused by some of the sulfate coming down as $\mathrm{Fe}_{2}\left(\mathrm{SO}_{4}\right)_{3}$.

Slow ignition with good access of air will avoic reduction of $\mathrm{BaSO}_{4}$.

\section{Sulfide Sulfur}

In this method, sulfide sulfur is determined by evolution as hydrogen sulfide $\left(\mathrm{H}_{2} \mathrm{~S}\right)$ from an acid solution of the cement into a solution of ammoniacal zinc sulfate $\left(\mathrm{ZnSO}_{4}\right)$. The sulfide sulfur is then titrated with a standard solution of potassium iodate $\left(\mathrm{KIO}_{3}\right)$. Sulfites, thiosulfates, and other compounds intermediate between sulfides and sulfates are assumed to be absent. If such compounds are pres ent, they may cause an error in the determination

The evolution method for sulfide sulfur [13] is not regarded as being the most accurate available However, it is fairly rapid, and even though all the assumptions upon which it is based may not holc rigidly, it is widely used throughout industry.

\section{Loss on Ignition}

In this method, the cement is ignited in a muffle furnace at a controlled temperature. The loss is assumed to represent the total moisture and carbon dioxide $\left(\mathrm{CO}_{2}\right)$ in the cement. This procedure is not suitable for the determination of the loss on ignition of portland blast-furnace slag cement and of slag cement.

\subsection{Causes of Variations}

High Results for Portland Cement. If the ignition temperature is too high, approaching $1,200{ }^{\circ} \mathrm{C}$, $\mathrm{SO}_{3}$ will be lost and some alkali volatilized. This will not only cause high results but will make it difficult to attain constant weight. A muffle furnace with an accurate temperature control is much to be preferred to ignition over a gas burner where the temperature can only be estimated. A 1 ह sample of hot cement takes a long time to coo in a desiccator. If it is weighed slightly warm, low weights can be obtained which cause high results. Generally, at least $1 \mathrm{hr}$ in the desiccator is required.

Sulfide-Containing Cements. Work of severa investigators has shown that the regular ignition loss procedure used in the analysis of portland cement is not applicable to cements containing sulfide constituents. ASTM and Federal methods have been revised to include suitable corrections. based on an additional sulfate determination performed on the ignited material together with suitable calculations.

Chaiken [14] indicated that a direct ignition method utilizing a helium atmosphere gave satisfactory results for blast-furnace slag cements.

\section{Sodium Oxide and Potassium Oxide.}

The specification methods cover the determination of sodium oxide and potassium oxide by flame photometry using the direct intensity procedure.

\subsection{Causes of Variations}

No attempt will be made to discuss the gravimetric determination of sodium oxide and potassium oxide in cement because it has been rather extensively covered in standard texts [6, pp. 925-930] and is now seldom used because of the greater ease of using flame photometry for the purpose.

In general, the flame photometric determination of potassium is rather straightforward and not subject to many sources of error within the accuracy generally required in cement analysis. The same cannot be said for the sodium determination. Errors, if present, generally tend to give slightly low results. The calcium present emits light in the same wavelength region, $589 \mathrm{~nm}(\mathrm{~m} \mu)$ at which sodium is measured. Silica, present in varying amounts in cement, inhibits the emission of calcium. Because the standard solutions used do not normally contain silica, this leads to somewhat low results for sodium (by a few hundredths of a percent) unless the silica is removed [15]. In fact, one or two cements manu. factured domestically contain such a low content of $\mathrm{Na}_{2} \mathrm{O}$ that some flame photometers indicate a slight negative $\mathrm{Na}_{2} \mathrm{O}$ content if silica is not removed. It is rather embarrassing to try to report a negative $\mathrm{Na}_{2} \mathrm{O}$ content for a sample of cement. Flame photometers equipped with adjustablewidth slits can be made to minimize this effect by using a rather narrow slit. Some older flame photometers of the motor-driven chopper type tend to give low results if the motor mountings become loose.

If the standard solutions are stored in glass bottles for several months, a small amount of sodium may be leached from the glass. This makes the actual sodium content of the solution higher than its nominal value. This can cause results reported for sodium oxide to be low by a few hundredths of a percent. An exchange between constituents of the glass and the solution may occur under some conditions. The best remedy is to store the standard solutions in polyethylene bottles. These have the added advantage of not supplying any chips of glass to plug up the atomizer. 


\section{Phosphorus Pentoxide}

A spectrophotometric method is applicable to the determination of phosphorus pentoxide in portland cement. Under the conditions of the test, no constituent normally present in portland cement will interfere.

Such a method has been adopted by ASTM. This method should solve most of the difficulties in this determination that have bothered chemists in the past.

A gravimetric method for the determination of phosphorus pentoxide is being considered as a
Federal method. It is a modified form of the previous ASTM gravimetric procedure. The changes include addition of a measured volume of a standard solution of phosphate to each sample as well as to the blank. This phosphate is added to minimize the tendency for formation of supersaturated solutions. Filtrates from the magnesium ammonium phosphate precipitation should not be discarded for several days. If any postprecipitation occurs, the precipitate should be filtered off, ignited, and the weight so obtained added to that already found.

\section{Manganic Oxide}

In this procedure, manganic oxide is determined volumetrically by titration with sodium arsenite solution after oxidizing the manganese in the cement with sodium metabismuthate $\left(\mathrm{NaBiO}_{3}\right)$.

\subsection{Causes of Variations}

The bismuthate method for determining manganic oxide [7, pp. 117-118 and 6 , pp. 443-446] is fairly straightforward. A few precautions might be empha- sized. It is important that the $1: 33 \mathrm{HNO}_{3}$ added after oxidation with $\mathrm{NaBiO}_{3}$, be completely freed of $\mathrm{HNO}_{2}$ by boiling. In the titration it may take practice to recognize the end point. This is the point at which no further color change can be noted on further addition of sodium arsenite. The end point of the solution should be observed in a strong light and against a white background. It is suggested that a spectrophotometric method for determining manganic oxide in portland cement would be a welcome addition to the specification methods.

\section{Insoluble Residue}

This method or any other method designed for the estimation of an acid-insoluble substance in any type of cement is empirical, because the amount obtained depends on the reagents and the time and temperature of digestion. If the amount is large, there may be a little variation in duplicate determinations. The procedure should be followed closely in order to reduce the variation to a minimum. When the method is used on blended cement, the decomposition in acid is considered to be complete when the portland cement clinker is decomposed completely. An ammonium nitrate solution is used in the final washing to prevent finely ground insoluble material from passing through the filter paper.

Halstead and Chaiken made a thorough study of the various factors affecting results obtained for the insoluble residue determination. Their published [16] recommendations have been used as the basis for recent revisions in ASTM and Federal specification methods. These modifications became necessary largely because the previous specification methods were not giving reproducible results for slag cements. These investigators recommended more specific requirements for heating equipment, dilution and digestion techniques, and thorough washing.

\section{Concluding Remarks}

It is generally recognized that analytical chemistry still is a mixture of science and art. As long as this situation prevails there will be differences in results obtained by different analysts for the same sample of material. The suggestions given in this paper are presented with the hope that they may be of some assistance in minimizing these differences in the analysis of cement.

The author acknowledges advice and assistance of Paul Pontius, of the Mass and Volume Metrology Branch of NBS, on material pertaining to weighing and weighing equipment. 



\title{
Part II. Possible Causes of Variation in Physical Tests of Portland Cements
}

\author{
John R. Dise*
}

\begin{abstract}
The physical properties of portland cement for which specification requirements have been developed are Fineness, Soundness, Time of Setting, Heat of Hydration, False Set, Air Content of Mortar, Compressive Strength, and Tensile Strength. Fineness tests are made on the cement itself; soudness, time of setting, heat of hydration and false set tests are made on pastes consisting of cement and water. Air content, compressive strength, and tensile strength tests are made on mortars consisting of cement, water, and a natural silica sand. In the following discussion of the possible causes of variation in these tests, particular attention is given to matters not already covered in detail in current publications. Some background information, including the year in which each method was first published by the American Society for Testing Materials, has been incorporated in the belief that it will foster greater appreciation for the efforts that have been expended in the development of the details of the tests. A brief description of each method has also been included in order that the discussion might have more meaning for a casual reader.
\end{abstract}

Key Words: Portland cement; physical tests.

\section{General Considerations in the Physical Testing of Cements}

Discussions of important considerations which are generally applicable to several or all test pro. cedures follow. It is intended that the pertinent parts of this section be considered an integral part of all subsequent sections.

\subsection{Laboratory}

(a) Temperature and relative humidity. The atmosphere of a laboratory can have a significant effect upon the behavior of mixes and test specimens. The standard methods of test for cements require that the relative humidity be maintained at not less than 50 percent, and the temperature between 20.0 and $27.5{ }^{\circ} \mathrm{C}$. In nearly all instances, automatically controlled conditioning equipment must be used in order to accomplish this. Drafts of air as well as low relative humidity can cause rapid evaporation of water from both mixes and specimens, and therefore work benches and testing apparatus should be shielded from excessive drafts from air conditioner duct outlets. Shielding from direct sunlight and local sources of heat such as radiators, steam pipes, hot plates, autoclaves, and ovens is also necessary.

(b) Lighting. The laboratory should be evenly illuminated with natural or artificial light so that operators will have no difficulty in reading instruments and gages or dials on test apparatus.

(c) Arrangement of equipment. Equipment should be so located that all items are readily accessible to laboratory personnel. Crowding of apparatus is to be avoided because this promotes carelessness in testing and creates safety problems.

\subsection{Treatment of Samples}

Aeration of cement markedly affects its physical

*Manager, Cement and Concrete Reference Laboratory, National Bureau of Stand ards, Washington, D.C. 20234. characteristics. For this reason, samples should be kept in air-tight, moisture-proof containers from the time they are taken until all tests are completed. Before testing, each sample should be passed through a No. 20 sieve in order to mix the sample, break up lumps, and remove foreign materials. Foreign materials and hardened lumps that do not break up on sieving or brushing should be discarded. An unusual amount of lumpy material may be an indication that moisture is present in the sample.

\subsection{Mixing Water}

In general, water fit for drinking is considered to be satisfactory for use in the testing of cement. Water from specimen storage tanks should not be used in the preparation of mixes. In instances where the suitability of the mixing water is questioned, duplicate tests using distilled or demineralized water may provide helpful information.

It is required that the temperature of mixing water be maintained between 21.3 and $24.7^{\circ} \mathrm{C}$. Since the temperature in outside pipes will vary over a broad range in any 12 -month period, it is usually necessary to make special provisions for bringing the temperature of tap water within the specified range prior to use.

With respect to time of setting and strength tests, it may be helpful to bear in mind that warm water hastens the hardening of cement and cold water retards it.

\subsection{Measurement of Mixing Water}

Mixing water should be measured in a clean glass graduate of the capacity and type specified in the applicable test method. In no case should the capacity be more than twice the volume required in the mix. A graduate which is not clean will not deliver the indicated amount of water, and for that 
reason frequent cleaning with dilute $\mathrm{HCl}$, or a suitable glassware cleaning solution, is recommended.

Significant errors can sometimes be attributed to bad practices in reading graduates. A technique which avoids a number of possible variations consists of permitting the filled graduate to come to rest in a vertical position while it is held lightly at the top between the tips of two fingers; after which the elevation of the hand is adjusted to bring the bottom of the meniscus into a horizontal plane with the line of sight. The reading is made using the bottom of the meniscus.

The degree of uniformity being attained in these measurements should be checked periodically by weighing a series of measured volumes of the same magnitude on a mix balance. In this check, the graduate may be used as both the weighing container and the measuring device. It may be of interest to compare the weights thus obtained with the theoretical weight of a given volume of water, at the temperature involved, as derived from a standard volumetric table.

\subsection{Standard Sands}

The two gradings of natural silica sand from Ottawa, Ill., used in making mortars for test purposes are customarily referred to as Standard Sand and Graded Standard Sand. Because a number of other gradings are also prepared by the processing plants, it is advisable for a laboratory to check each new shipment to ascertain that the proper sand has been received.

Contamination of the sand with an agent capable of entraining air in mortars sometimes occurs during processing, shipment, or storage. In many instances, the first evidence of an accident is a substantial increase in the air content, or a noticeable decrease in the strength, of test mortars. The test method for air-entrainment of standard Ottawa sand developed by DeFore and Corah [17] provides a way in which to determine if a given lot of sand is contaminated. Another method is to run duplicate tests with sand considered to be uncontaminated.

\subsection{Weighings}

(a) Mix balance. The balance should be located on a sturdy table with a rigid, nonskid top. The top should be level, and the point at which the balance is placed should be shielded from direct sunlight and from stray currents of air. The balance should be capable of weighing loads of 1 to $2 \mathrm{~kg}$ with an accuracy of $\pm 1 \mathrm{~g}$.

(b) Mix weights. A common mistake in weighings is the use of mix weights which do not conform to the accuracy requirements of the various cement test methods. The difficulty can usually be attributed to the loss of slugs from a "two-piece" weight, or surface wear on the botiom of a solid weight. Because of the wear problem, it is recommended that weights be lifted rather than skidded from one location to another, and that they be stored in a suitable block when not in use. Every laboratory should be equipped with a spare set of new mix weights that can be used for periodic checking of the weights in daily use.

\subsection{Timing Device}

One or more timing devices, preferably of the type equipped with sweep second hands, should be so located that operators can conveniently observe the time from any point in the laboratory. In general, stop watches and pocket watches are less suitable than devices such as wall clocks and bench-type timers with large faces.

\subsection{Oiling of Molds}

Several of the test procedures require that the surfaces of molds be thinly covered with mineral oil. Nondetergent oil is preferable. Animal fats or vegetable oils should not be used in lieu of mineral oils. Reductions in the apparent strengths of mortars of 10 percent or more may be encountered when an unsatisfactory lubricant is used.

\subsection{Specimen Storage Facilities}

Well made specimen storage facilities are essential. Some of the important considerations are as follows:

(a) Temperature. It is required that the temperature of the air in a moist cabinet or moist room, and the temperature of the water in a storage tank, be maintained between 21.3 and $24.7^{\circ} \mathrm{C}$. Many cement testing laboratories have found it necessary to install automatic controls in order to maintain storage temperatures within these limits.

(b) Relative humidity. It is required that the moist closet or moist room be so constructed as to provide storage facilities for test specimens at a relative humidity of not less than 90 percent. Specimens in storage should both look moist and feel moist.

(c) Storage of filled molds. Molds containing specimens should be so stored that the upper surfaces are freely and uniformly exposed to the atmosphere of the moist storage unit. Molds should not be piled one upon the other in such a way that the plates of the upper molds exclude air from the specimens beneath. When sprays are used to humidify the moist storage unit, precautions should be taken to prevent water from falling upon the surfaces of freshly molded specimens.

\subsection{Storage Period for Molded Specimens}

Molded specimens are to be stored in a moist at mosphere until they have attained the age of $24 \mathrm{hr}$, at which time they are either tested or placed in water storage. In no case should specimens be removed from the molds until they are at least $20 \mathrm{hr}$ old. If removed before $24 \mathrm{hr}$ have elapsed, they 
should be placed on the shelves of the moist storage unit until the expiration of the 24-hr period.

\subsection{Removal of Specimens From Molds}

Specimens which are damaged during mold stripping operations should be discarded even though the damage may be considered to be slight. Damage to test specimens, and also to molds, can be minimized if a rawhide hammer is used to apply the gentle taps usually needed to break the bond between mold and specimen. When stripping is completed, care should be taken to ensure that mold parts are not inadvertently interchanged. In many instances, the dimensions of molds will not conform to specification requirements after an interchange of parts.

\subsection{Marking Specimens}

Reliable identification marks, preferably numerals, must be made on each test specimen if errors due to mistaken identity are to be avoided. The marks should be made on paste specimens, such as the Gilmore pat and the autoclave bar, immediately after they are formed. Identification tags should be used for freshly molded mortar specimens such as briquets and cubes. Under no circumstances should identification of a specimen depend upon its position on a shelf or table, or its proximity to a marked specimen. When mortar specimens, such as briquets and cubes, are removed from moist storage, the identification should be marked on the bottom surfaces with a soft graphite crayon after the plates have been removed, but while the specimens are still in the molds. Colored crayons should not be used because their marks may fade very quickly after specimens are placed in a water storage tank. The practice of using a sharp tool to scratch marks in the surfaces of mortar specimens is objectionable.

\subsection{Trowels}

The specifications require that the trowels used in making specimens have steel blades, 4 to $6 \mathrm{in}$. in length, with straight edges. Many operators have found that a slightly curved blade is preferable for making briquets. Briquet trowels should not be used for other purposes. Damaged, blunt, or badly worn implements should not be used in any operation.

Excessive troweling of the paste in a Vicat ring or an autoclave bar mold often occurs after the surface of the material is torn in the process of slicing off that which projects above the top edge of the mold. Torn and uneven surfaces will be encountered frequently when an implement with blunt edges is employed, and therefore, it is advantageous to reserve a trowel with specially sharpened edges for use in the preparation of paste specimens.

\subsection{Rubber Gloves}

Rubber gloves are used during the preparation of autoclave bars and mortar briquets, and in several other testing operations where it is undesirable to have the hands come into contact with pastes or mortars. Comfortable, well-fitting, pliable gloves are necessary for accurate work.

\subsection{Care and Cleaning of Apparatus}

It is usually difficult, and sometimes impossible, to obtain satisfactory results with testing apparatus that is not clean, and it is to be concluded that continuous attention should be given the important matter of cleanliness. However, it must be remembered that poor cleaning techniques may create rather than solve problems. In this connection, mention is made of the fact that power-driven wire brushes and brushes with steel bristles are not suitable for use in cleaning molds. Also, that the use of kerosene, which may act as an air-detraining agent, in the cleaning of molds and mixing equipment may cause anomalies in test results.

Situations frequently arise wherein a laboratory finds it necessary to adjust the weight or volume of test apparatus. A common mistake on these occasions is failure to clean the apparatus prior to starting the adjustment. Another is the use of an inaccurate balance or weight for checking the work. These mistakes may have a very significant effect on tests employing a Vicat apparatus, the Gillmore needles, or a $400-\mathrm{ml}$ measure.

\section{The Determination of Fineness}

Fineness has long been recognized as one of the important physical properties of a cement. Early tests were based on the use of sieves and it was not until 1933 that a satisfactory replacement, the Turbidimeter Fineness Method (ASTM Designation: C115), was introduced. Another new test, the Air Permeability Fineness Method (ASTM Designation: C204), was introduced in 1943. Currently, both of these procedures are used as standard tests of cement.

\subsection{Common Causes of Variations}

Although the two fineness tests are distinctly different in technique and theory, there are a num. ber of considerations which are of importance in either procedure. Some of these are presented herewith.

(1) Problems with the standard fineness sample. Although great care is taken in the blending and packaging of standard fineness samples, an occa- 
sional vial is found to be unsuitable for calibration purposes. It therefore is advisable to check the calibration of an instrument with a freshly opened sample whenever an unexpected difficulty is encountered. The risk of contaminating fresh samples with glass chips when the containers are opened may be reduced if opening is accomplished by inverting the vial and pressing the sides in the empty sections against a thin, curved, high-resistance wire mounted between the terminals of a small transformer.

(2) Exposure of apparatus to a source of variable heat. The location of a turbidimeter or an air perme. ability apparatus above, or near, a source of variable heat such as a radiator, hot plate, oven, or autoclave, may cause considerable variation in test results.

(3) Errors in calculations. Among the common errors in calculations are the following: (a) Mistakes in the use of arithmetic, algebra, or logarithms. (b) Errors in the transcription of figures. (c) Mistakes in the use of slide rules and other calculating devices. (d) Selection of the wrong equation for a basic calculation.

(4) Conversion of one test value to another by means of a factor. Since the air permeability value is frequently about 1.7 times greater than the turbidimeter value, this factor is sometimes used in converting from one test value to the other. The practice is unsound because the results in these tests may be affected by such unpredictable influences as differences in the ignition loss of a cement from day to day, or differences in the particle size distribution caused by variations in grinding, and values obtained in this manner may be seriously in error.

\subsection{The Turbidimeter Fineness Test}

The method of test for fineness of portland cement by the turbidimeter was introduced in a paper presented by L. A. Wagner in 1933 [18], and adopted as a standard test for cement in 1934. The procedure provides for the determination of specific surfaces by measurement of the turbidities of cements in liquid suspensions. Essentially, the turbidimeter consists of a source of light of constant intensity adjusted so that approximately parallel rays of light pass through a suspension of cement in clear white kerosene and impinge upon the sensitive plate of a photoelectric cell. The current generated by the cell is measured with a microammeter and the indicated reading is a measure of the turbidity of this suspension. The turbidity is in turn a measure of the surface area of the suspended cement.

An attractive feature of the test is that it provides a means for determining the particle size distribution as well as the specific surface of portland cements. This advantage has been nullified to a certain extent, however, by the difficulties a laboratory encounters in maintaining all of the various elements of the apparatus in satisfactory operating condition, and in teaching new operators to make the determination. It is important to bear in mind that the test is not intended for use in determining the fineness of materials other than portland cement.

\subsubsection{Causes of Variations}

\section{A. Apparatus}

(1) Apparatus improperly mounted. Vibration of the wall, or other object, to which the shelf supporting the sedimentation tank has been fastened may disturb the suspension and thereby affect test results. The shelf should be so located that the indicator on the scale on the side of the case reads zero when the center of the slot in the photoelectric cell is at the same elevation as the surface of the liquid in the tank.

(2) Water cell in poor condition. When the cell is not completely filled with water, a difference in transmission of light may be encountered above and below the water line. Also, a wavering film of matter inside the cell, or dirt and sedimentation lines on the glass ends of the cell, may influence the transmission of light. Keeping the cell completely filled with distilled water helps to avoid these problems.

(3) Sedimentation tank in poor condition. Scratches on the faces of the sedimentation tank may affect the transmission of light.

(4) Reflection of light from bright surfaces inside turbidimeter case. It is required that the interior of the case, and the exterior surfaces of the shelf, parabolic reflector, water cell, shield, and photoelectric cell hood be painted with a dull, optical black paint. In addition, the cabinet should be free of light reflecting dust, light-colored wiring, and shiny pieces of metal, and the gaskets used to seal the end of the water cell should be black.

(5) Trouble in the electrical system. Among the possible causes of difficulty are the following:

(a) Corrosion of electrical contacts and of the wires in the rheostats.

(b) Broken or loose connecting wires.

(c) A weak storage battery.

(d) Deterioration of the photoelectric' cell. Photoelectric cells tend to have different fatigue characteristics, and therefore the cell always constitutes a potential source of difficulty even though it may have been in use for only a relatively short time.

(e) Trouble with the light bulb. Malfunctioning of a part inside the bulb or looseness of the bulb in the socket can cause erratic microammeter readings.

(f) Looseness of the reflector in its holder.

(g) Improper focusing of the light beam.

(h) Changes in the color, or intensity, of light emitted by a bulb after prolonged usage.

(i) Malfunctioning of voltage regulator. In laboratories where storage batteries have been replaced with a voltage regulator, malfunctioning of the regulator may constitute a problem.

(6) Trouble with the microammeter. Among the possible difficulties with the microammeter are the 
following:

(a) Damage in usage. A bent tip on the indicating hand may be an indication that the instrument has been overloaded.

(b) Internal corrosion of parts while instrument is in storage. A microammeter that has not been used for some time may have to be "exercised" before it will give uniform readings.

(c) Static charges on the instrument, or on the person using it. In some instances, it has been found necessary to ground both the microammeter and the operator.

(d) Location of the microammeter on a table containing magnetic material, or near some strong external magnetic field.

(7) Variations in the character of the suspension. Among the causes of variations in the suspension are the following:

(a) Appreciable variations in room temperatures.

(b) Use of a suspending medium other than clear, white kerosene.

(c) Traces of water in the kerosene. Water may cause foaming inside the tank during agitation of the suspension.

(d) Changes which often occur in oleic acid or linseed oil with age or exposure to heat and light. When difficulties are encountered in calibrating the apparatus, one of the first corrective actions should be to obtain fresh supplies of dispersing agent and kerosene. In general, technical grade oleic acid does not make a suitable dispersing agent.

(8) Trouble with the timing buret. Lint in the capillary of the buret, even though practically invisible, can slow down the flow of kerosene and thereby. cause an appreciable variation in test results. Accordingly, utmost precautions should be taken to keep lint out of the buret, and the kerosene. As a safeguard, a filter made of No. 325 sieve cloth should be placed across the top of the buret whenever kerosene is being added, and the top opening should always be covered when the buret is not in use. Use of an improperly made or a broken timing buret is to be avoided.

(9) Problems with the wet sieving apparatus. Consideration should be given to the following:

(a) Improper nozzle design. It is difficult to obtain good reproducibility in test results if the angle of inclination of the intermediate and outer rows of holes does not conform with specification requirements.

(b) Variations in water pressure. Among the contributing factors are plugging of holes in the spray nozzle, fluctuations of the pressure in the water line, and errors in setting the pressure. The latter difficulty may be caused by the use of a badly marked or inaccurate gage, or by the use of a gage which does not conform to the scale division, maximum capacity, and nominal diameter requirements of the specifications. It should be noted that a gas gage is not suitable for use with water unless it has been modified for such usage. Fluctuations in line pres- sure may be reduced or eliminated by the installation of a pressure regulator in the line back of the gage. The overall performance of the spray assembly should be checked periodically by collecting and weighing the amount of water passing through the nozzle in one minute.

(c) Unsatisfactory sieves. One possible cause of difficulty in wet sieving operations is the use of lacquered sieve frames. During a washing, the lacquer tends to flake off and fall onto the screen. This increases the amount of material remaining on the screen at the end of a test. Another possible cause of difficulty is use of a damaged screen. Laboratory personnel must be careful not to injure screens during the blotting operation subsequent to washing or during cleaning. In the event an accident occurs, the damaged sieve should be retired from service. Plugging of holes in torn screens with solder is undesirable. A third possible cause of difficulty is the use of screens in which the openings have been enlarged by immersion in aqua regia to change the sieve correction factor.

\section{B. Test Procedure}

(1) Improper cleaning of tank prior to starting test. If an oily film has accumulated on the interior faces of a tank, it should be removed with a "lint-free" wiper before a test is started. A "squeegee" of synthetic rubber makes a good wiping device. Wiping of a dry tank with a dry cloth is to be avoided because this may create static charges on the tank.

(2) Variations in the agitation of suspensions. Variations in the agitation process include allowing the cement to slide along the inner faces of the tank during rotation, and loss of a part of the suspension during alternate inversions. A number of laboratories have found that the use of a rotatable tank holder helps to promote uniformity in agitation operations. Customarily, this holder is provided with an adjustable screw in the center of the top to hold the glass lid of the tank in place, and so designed that it can be mounted to a wall by a pivot arrangement at its center, and rotated through $180^{\circ}$ by means of a handle located near one end.

(3) Fouling of tank faces during handling of the tank. Care must be taken, especially during the agitation process, to avoid getting liquid or finger prints on the faces of the tank which are to be placed in the path of the light. If it becomes necessary to clean the tank after agitation, the possibility that a static charge may be created on the faces of the tank as a result of wiping must be considered.

(4) Variations in the wet sieving operation. Among the possible causes of difficulty are the following:

(a) Errors in weighing the sample or the residue. Since the weight of the material retained on the screen is often less than 10 percent of the original weight of the sample, errors in weighing can have a significant effect on test results. It therefore is recommended that both the sample and the residue be weighed to at least $0.001 \mathrm{~g}$ using the same pan 
of the same analytical balance and the same set of analytical weights.

(b) Improper manipulation of the sieve. Precautions should be taken to avoid loss of cement due to splashing at the beginning of the wet sieving operation. After washing begins, strict efforts should be made to keep the sieve in the same horizontal plane at all times. Such practices as holding it at an angle or moving it up and down preclude reproducibility. In consideration of the importance of this detail, the use of a small wooden platform to support the sieve in the proper position throughout the washing period is strongly recommended. The sieve should be kept in motion in order to prevent the accumulation of material around the edge.

(5) Errors in calculation. A common source of error is the failure to use standard procedures in the calculation and application of correction factors for No. 325 sieves.

\subsection{The Air Permeability Fineness Test}

The method of test for fineness of portland cement by the air permeability apparatus was introduced in a paper presented by R. L. Blaine in 1943 [19], and adopted as a standard test for cement in 194.6. The procedure provides for the determination of specific surfaces by measurement of the rates of air flow through prepared beds of cements of definite porosities. Essentially, the air permeability apparatus consists of a permeability cell and a $U$-tube manometer filled to about the midpoint with a suitable liquid. The test is accomplished by attaching the cell, containing a carefully measured amount of cement, to the manometer and evacuating the air in one arm thereof until the liquid rises to a point just beneath the cell, after which the liquid is released and the time required for the meniscus to fall through a distance of approximately $5.5 \mathrm{~cm}$ recorded. The specific surface is then calculated from this time-of-flow determination.

The procedure is favored by many investigators because it is economical to perform, and because it can be used to determine the fineness of materials other than portland cements. It is to be noted that the test is not suitable for determining the specific surface of materials finer than $7,000 \mathrm{~cm}^{2}$ per $\mathrm{g}$, or the specific surface of porous materials such as diatomaceous earth and fly ashes containing porous cinders. Also, that in testing materials other than portland cement, it is generally necessary to use a specific gravity other than that (3.15) which is customarily assigned to portland cement.

Air permeability fineness determinations are sometimes influenced by factors which are peculiar to tests in a single laboratory, or to those in a small group of laboratories, and it is not uncommon to find that a modification of the standard procedure has been made in an effort to compensate for such influences. It is very probable that some of the variations in comparative test results can be attributed to the fact that values reported by several laboratories were obtained by a modified procedure rather than the standard procedure because the operators concerned were not aware of the difference in techniques.

\subsubsection{Causes of Variations}

\section{A. Apparatus}

(1) Nonconformance of permeability cell with specification requirements. Variations in the volume of the test bed may result from wearing of or damage to the cell and plunger, or nonplaneness of the perforated disk. When a unit is being used regularly, the dimensions and the physical condition of the component parts should be checked at least once in every six months, and the volume of the compacted bed should be checked at least once in every twenty-four months. In checking dimensions, close attention should be given to the clearance between the plunger and cell; particularly so if nonstandard plastic plungers are being used. If during the examination of physical characteristics the disk is found to be warped, it should either be replaced or marked in such manner that the operator will remember to place it in the cell with the same side up for every test. If one or more parts are replaced, due thought should be given to the possibility that a new plunger manufactured to specification requirements might not be suitable for use with an old cell which still meets specification requirements, or that a new disk manufactured to specification requirements may not be suitable for use with an old cell and plunger which still meet specification requirements. It should also be borne in mind that the apparatus must be recalibrated with a standard sample whenever any part of the cellplunger assembly is replaced or altered by repairs.

(2) Uneven disks of filter paper. It is difficult to seat disks of filter paper inside the cell if the edges are torn or uneven or badly curled from the cutting process. Disks having these characteristics should not be used.

(3) Unsatisfactory stopcock lubricant. Stopcock lubricants sometimes foul the upper part of the manometer to the extent that droplets of manom. eter fluid will cling to the inner surfaces after the liquid has receded. When this occurs, the inside of the manometer should be cleaned, and a check made to insure that petrolatum, or a petrolatum base stopcock lubricant, is available for future use. One way in which a manometer tube may be cleaned is under the supervision of an expert chemist, to fill it with an organic solvent to remove all traces of manometer fluid, rinse out the solvent with water, allow the interior to dry, fill it with a 20-percent solution of fuming sulfuric acid which is then allowed to stand for a period of from 2 to $12 \mathrm{hr}$, and finally rinse with water to remove the acid.

(4) Incorrect amount of fluid in the manometer The specifications require that the manometer be filled with fluid to the midpoint. Since the calculated midpoint often falls either above or below the 
lower mark, in the interest of uniformity, it is customary to consider that the lower mark is at the midpoint of the tube. When this feature is checked, it should be remembered that the level of the liquid will often be 2 to $3 \mathrm{~mm}$ below the normal level immediately after a test.

(5) Changes in viscosity of manometer fluid. Use of a liquid whose viscosity may vary appreciably with changes in temperature is undesirable.

(6) Inaccurate timer.

\section{B. Test Procedure}

(1) Errors in calibration of apparatus. Among the common errors in calibration are the following:

(a) Incorrect porosity of bed. A loosely compacted test bed is highly sensitive to slight bumps whereas a tightly compacted bed may spring back when the plunger is released. Since the porosity of bed has an important relationship to these problems, it is essential that a suitable value be selected. In general, a value greater than 0.500 should be used for materials finer than Type I cement, and a value less than 0.500 should be used for coarser materials.

(b) Failure to fluff the standard fineness sample prior to use.

(2) Cement not at room temperature at time of test.

(3) Variations in the volume of the test bed. Variations in the volume of the bed may be caused by the following:

(a) Failure to seat filter papers properly. It is required that a rod slightly smaller than the cell diameter be used to press the edges of the bottom piece of filter paper against the metal disk.

(b) Failure to level the surface of the bed prior to compaction. It is required that the side of the cell be tapped lightly in order to level the bed of cement. Too much tapping is undesirable, particularly when coarse cements are being tested.

(c) Loss of cement around sides of rapidly descending plunger.

(d) Improper compaction techniques. Among these is rotation of the plunger after it comes in contact with the top piece of filter paper. (e) Too rapid removal of plunger after compaction.

(4) Errors in timing. Such errors are frequently encountered where the operator fails to use the bottom of the meniscus of the manometer liquid in gaging when to start and stop his timer.

(5) Leakage of air around outside of cell during test.

(6) Theoretical errors. A common mistake is the failure of an individual operator to calibrate himself by determining his own $T_{s}$ for the standard fineness sample, or a suitable reference sample. Another is the selection of the wrong equation for calculation of inneness. The latter problem may be avoided by using the following composite equation for all calculations:

$$
S=\frac{S_{s} \sqrt{T}}{\sqrt{T_{s}}} \times \frac{p_{s}\left(1-e_{s}\right)}{p(1-e)} \times \frac{\sqrt{n_{s}}}{\sqrt{n}} \times \frac{\sqrt{e^{3}}}{\sqrt{e_{s}^{3}}}
$$

where:

$S=$ specific surface in sq $\mathrm{cm}$ per $\mathrm{g}$ of the test sample,

$S_{s}=$ specific surface in sq $\mathrm{cm}$ per $\mathrm{g}$ of the standard sample used in calibration of the apparatus,

$T=$ measured time interval in seconds of manometer drop for test sample,

$T_{s}=$ measured time interval in seconds of manometer drop for standard sample used in calibration of the apparatus,

$n=$ viscosity of air in poises at the temperature of test of the test sample,

$n_{s}=$ viscosity of air in poises at the temperature of test of the standard sample used in calibration of the apparatus,

$e=$ porosity of prepared bed of test sample,

$e_{s}=$ porosity of prepared bed of standard sample used in calibration of apparatus,

$p=$ specific gravity of test sample (for portland cement a value of 3.15 shall be used), and

$p_{s}=$ specific gravity of standard sample used in calibration of apparatus (assumed to be 3.15 ).

\section{Consistency}

Both hand mixing and mechanical mixing procedures are used in the preparation of pastes and mortars of the consistency required for the standard tests of portland cement. Pastes for heat of hydration tests are first mixed by hand with a spatula, and then with an electric stirrer, using the amount of water indicated in the test method. All other pastes are mixed with a mechanical mixer and their consistencies measured with the Vicat apparatus. Standard 1:3 mortars for tensile strength specimens are mixed by hand using a calculated amount of water. All other mortars are mixed with a mechanical mixer and their consistencies measured with the 10-in flow table.

\subsection{Mechanical Mixing of Pastes and Mortars}

Continuing interest in the use of mechanical mixing for the preparation of pastes and mortars led to the adoption of a standard mixing device in 1953. A method for mechanical mixing of plastic mortars was also put into use at that time. A method for mechanical mixing of pastes of normal consistency was adopted in 1959. The mixer and the two mixing procedures are described in ASTM Designation: C305. A separate method for mechanical mixing of pastes for false set tests was added to the standard procedures in 1962. This method is described in 
ASTM Designation: C451. One of the most common difficulties with these mechanical mixing procedures has been inadequate mixing of pastes and mortars due to excessive clearance between the end of the mixing paddle and the bottom of the mixing bowl.

\subsubsection{Causes of Variation}

\section{A. Apparatus}

(1) Nonconformance of mixer design with specifcation requirements. It is required that the mixer be of the epicyclic type, that the speed be established by mechanical means, that the mixing bowl have a nominal capacity of 5 quarts, and that the paddle and bowl be made of stainless steel. The Model N-50 Mixer, made by the Hobart Manufacturing Co., is considered to conform with these requirements. However, it is to be noted that the bowl and paddle often supplied as original equipment are not made of stainless steel, and therefore must be replaced if the mixer is to be used in the testing of cement. Mixers which do not conform with specification requirements should not be used. Paddles equipped with wipers should not be used unless authorized.

(2) Failure to provide correct current for mixer motor. Mixer motors are customarily designed to operate on $115 \mathrm{~V}, 60$ cycle, alternating current. -Speed control problems will be encountered when efforts are made to operate the conventional motor at a different voltage or frequency.

(3) Failure to maintain correct paddle to bowl clearances. Incorrect clearance between the end of the paddle and the bottom of the bowl is a frequent problem in mechanical mixing procedures. When the clearance is too great, materials accumulate around the bottom of the bowl with the result that the mixture obtained is not of the expected consistency. When the clearance is too small, the paddle grinds up a portion of the standard sand, thereby changing the consistency of the mix and often causing excessive wear of both the paddle and the bowl.

(a) Adjustment of clearances. Small adjustments can often be made simply by bending the lugs on the side of the bowl. (Note: In general, the use of washers beneath the lugs to raise the bowl is unsatisfactory.) Major adjustments can be made by raising or lowering the motor housing, or by having a competent machinist rework a given paddle to fit a given bowl. Intermediate adjustments can be made by means of the prescribed adjustment bracket.

(b) Marking of bowls and paddles. Since they are seldom, if ever, identical in every small detail, paddles and bowls, in most instances, cannot be interchanged at random after clearances have been adjusted for a given mixer-paddle-bowl combination. Therefore, if equipment is carefully adjusted in such manner that two paddle-bowl sets can be used with a single mixer, each set must be match-marked so that the proper combination can be easily recognized. Where more than one mixer is in use, each mixer-paddle-bowl set must be match-marked.

(c) Correction for wear. Wearing of the driving gears or wearing of the slot in the paddle which holds it to the drive shaft may create play which permits the paddle to come close to or touch the side of the bowl as it rotates. Replacement of the gears or paddle, or repair of the slot will usually eliminate this problem.

(4) Bowl damage. Bowls may be accidentally damaged by dropping of the bowl, dropping of the paddle into the bowl, or by raising the bowl into the mixing position before it is properly seated in the frame. Careless or nonprofessional efforts to repair a dent may result in a change in the form of the bowl which renders it unsatisfactory for use.

(5) Failure to provide a lid for the bowl. A cover is needed to prevent evaporation losses during pauses in the mixing operation. This lid should be made of material not attacked by the cement, and should be sufficiently rigid that it will lie flat across the top of the bowl. Rags should not be used in lieu of a lid.

(6) Leakage of oil from gear housing into mixing bowl. A change in the consistency of the mix may occur if oil falls into the bowl from the gear housing during a mixing operation. When a mixer has not been used for some time, the bowl should be checked for oil, and cleaned if necessary, prior to starting a test.

\section{B. Test Procedure}

(1) Use of wrong amount of cement and mixing water; or cement, sand, and mixing water.

(2) Failure to remove all moisture from paddle and bowl before use.

(3) Failure to introduce materials into the bowl in the prescribed sequence.

(4) Loss of materials as they are being introduced into the bowl. Accidental losses can be minimized by the use of a funnel-shaped hopper.

(5) Failure to follow the prescribed mixing procedure.

\subsection{The Normal Consistency Determination}

The amount of water to be used in preparing pastes for time of setting and autoclave expansion tests, and in preparing mortars for tensile strength tests, is established by the normal consistency determination (ASTM Designation: C190). The apparatus for this determination was developed out of equipment used in about 1818 by L. J. Vicat, Chief Engineer of Bridges and Roads in France [20], and the test had been in use for many years in both the United States and Europe prior to its adoption as a standard cement testing procedure in 1904. The method provides for the determination of the consistency of machine-mixed paste by observation of the depth to which the $1 \cdot \mathrm{cm}$ diam plunger of a Vicat apparatus penetrates a ring-confined sample during a 30-s period, and the paste is considered to be of normal consistency when the penetration is be. 
tween 9 and $11 \mathrm{~mm}$. One of the more important variables in this procedure is failure to observe the specified time limits on the various operations. It has been found that for normal portland cements two repeat tests in a laboratory can be expected to agree within 0.5 percentage points and test results between two laboratories can be expected to agree within 0.9 percentage points 95 percent of the time.

\subsubsection{Causes of Variations}

\section{A. Apparatus}

(1) Incorrect plunger weight. Incorrect plunger weight may result from loss of shot from the barrel of the plunger, reduction of weight due to loss of metal in a machining operation, accumulation of dirt on the plunger, or replacement of the $1-\mathrm{mm}$ needle. The weight may be adjusted by varying the amount of shot in the barrel (when construction of the apparatus permits); or by filing material away from, or adding solder to, the customary knurled knob on the needle assembly. When solder is added, it must be determined that the adjustment is permanent.

(2) Incorrect plunger diameter. The diameter of the plunger may be incorrect due to errors in machining or damage in usage. Also, a substantial reduction in diameter of the end of the plunger may occur over a period of time from polishing the sides with emery cloth.

(3) End of plunger in poor condition. The condition of the end should always be checked after an uncontrolled drop, or after it has come in forcible contact with a hard object.

(4) Frictional resistance to fall of plunger. Among the conditions which tend to retard the fall of the plunger are the following:

(a) Use of viscous oil or grease on plunger. The plunger should be oiled at the contact point with the frame. Only light oils are suitable for this purpose.

(b) Hardened cement or rust on the sides of the plunger.

(c) Accumulation of dirt at point where plunger contacts frame. Dirt will accumulate rapidly on the portion of the plunger that slides through the frame of the Vicat apparatus unless the operator develops the habit of holding the lower end while making adjustments of the zero setting.

(5) Vicat apparatus in poor condition. The apparatus is judged to be in poor condition if the indicator is bent or twisted in such fashion that it does not point to comparable lines on both scales; or if the scale is tarnished and difficult to read.

\section{B. Test Procedure}

(1) Failure to use the mechanical mixing procedure. Some laboratories have been reluctant to discontinue the former standard practice of mixing pastes by hand. It therefore is noted that the water requirement for hand mixing is usually greater than for mechanical mixing and that in many instances the difference will be on the order of 0.7 percent.
(2) Retempering to obtain paste of the desired consistency.

(3) Failure to completely fill the Vicat mold with paste. Such failures may be minimized if the ball of paste is gently shaken into an ellipsoidal shape while resting in the palm of the hand prior to insertion of the mass into the larger end of the mold.

(4) Failure to make the proper zero setting. It is a common practice to make the zero setting by adjusting the indicator to read zero when the bottom of the plunger is resting on the top of the side of the mold, which in turn is resting on the glass plate used with the mold. It is to be noted that this is only an approximation of the place where the surface of the paste will actually be. Individuals wearing bifocal glasses sometimes find it difficult to make an accurate setting.

(5) Improper release of the plunger. The manipulation of the setscrew holding the plunger must be such that the plunger will be released gently, quickly and completely.

(6) Failure to release the plunger exactly $30 \mathrm{~s}$ after mixing. The time that elapses between completion of mixing and release of the plunger has an important bearing on test results, particularly when cement with false setting characteristics, or highly plastic cements such as Type III or Masonry Cements, are under test.

(7) Vibration of the work table while penetration tests are in progress.

\subsection{The Flow Table Test}

A comprehensive specification (ASTM Designation: C230) for the 10-in flow table, based on the knowledge gained during more than 30 years of experimentation with and use of this device for measuring the consistency of mortars, was adopted in 1949. The apparatus consists essentially of a 10 -in diam rigid table, with a perpendicular shaft, mounted on an integrally cast rigid iron frame fastened to the top of a 300-lb concrete pedestal. Accessory items are a mold in the shape of the frustrum of a cone, and a specially marked caliper. The test is accomplished by leaving the amount of mortar required to fill the mold on the table while it is raised and dropped a specified number of times by means of an electrically driven cam fastened to the frame. The flow is the resulting increase in diameter of the mortar mass expressed as a percentage of the original base diameter.

\subsubsection{Causes of Variations}

All of the important requirements for the table are covered in detail in ASTM Specification C230, and a lengthy check list for use in trouble shooting is available [21]. Since so much information has already been printed, only a few causes of variations other than those taken into account in section 16 are presented herewith. 


\section{A. Apparatus}

(1) Nonconformance of apparatus with specification requirements. This is a common problem with brand new and old apparatus alike. New apparatus which does not conform to specification requirements should not be accepted. Old apparatus should be repaired or replaced whenever the following signs of wear or damage are noted:

(a) Damage to contact surfaces.

(b) Excessive clearances between bore and shaft.

(c) Leakage of water from beneath flow mold due to damage to bottom edge.

(d) Inaccurate flow measurements due to wearing of caliper.

(e) Curvature in straightedge of trowel used in striking excess material from the flow mold.

(f) Improper alinement of cam with table shaft due to bending of the threaded end of the cam shaft.

(g) Viscuous oil on flow table shaft.

(h) Loose mounting bolts.

(i) Unstable pedestal.

(j) Poor contact between plate and pedestal.

(k) Poor concrete in pedestal. All pedestals should be moist cured for at least 28 days prior to use.

(2) Failure to provide correct current for flow table motor.

B. Test Procedure

(1) Failure to dry and clean the table top prior to use.

(2) Variations in flling the flow mold. Variations in the amount of material contained within the mold may be caused by variations in compacting mortars into the mold, including the failure to use the prescribed 20 tamping pressures. The practice of throwing mortar into the mold also constitutes a variable. The mold should be held firmly against the table top during the filling operation in order to reduce seepage under the bottom edge.

(3) Failure to dry and clean the table top after filling the mold. Any water that may have seeped from beneath the mold, and all spilled mortar, should be wiped away prior to proceeding with the test.

(4) Errors in determining the flow. The flow is the increase in diameter of the mass of mortar expressed as a percentage of the original diameter. The flow caliper specified for use in measuring the flow is graduated to indicate one fourth of actual flow so that readings of four measurements may be added to give the flow value. Calipers graduated to read the flow directly in percent or percentage markings on table tops usually give less satisfactory values. In using the specified caliper due care should be exercised to avoid mistakes in readings and mistakes in adding the readings.

(5) Adjustment of flows by application of correction factors. A mixture of ground silica and mineral oil supplied by the Cement and Concrete Reference Laboratory has been used for a number of years as a means of gaging flow table performance. Some laboratories have attempted to correct mortar flow values by adding or subtracting the difference between assigned flow values and actual values obtained with the silica-oil mixture. Test results are not reliable when adjusted in this manner.

\section{The Autoclave Soundness Test}

Soundness tests have been used for many years to detect those qualities of a cement which tend to destroy its strength and durability, and at least four procedures employing artificial conditions which would hasten the development of such defects were either being used or studied in the early 1900's. An autoclave test was among these, and ultimately, in 1940, it was adopted as a standard test for cement (ASTM Designation: C151). The method of test for autoclave expansion of portland cement provides for the exposure of a prism ( 1 by 1 by 10 in) of hardened cement paste to a steam pressure of 295 psi (gage) within a specially designed autoclave for a period of $3 \mathrm{hr}$. Changes in length of the prism are measured by means of a suitable length comparator.

\subsection{Causes of Variations}

\section{A. Apparatus}

(1) Mold problems. The mold problems described below are frequently encountered:

(a) Use of multicompartmented molds. Single or double compartment molds are preferred because they make it possible to put bars in moist storage soon after molding is completed. (b) Thin end plates in bar molds. Thin end plates may permit the gage studs to become so deeply imbedded in the ends of bars that an accurate measurement of length cannot be obtained.

(c) Damaged gage studs. Use of gage studs with damaged contact points may cause an error in the measurement of a bar, particularly if the bar is inverted between the initial and final readings. For this and other reasons, each bar should be marked on one end to protect against inversion.

(2) Operational problems with the autoclave. The operation of the autoclave is an important factor in some soundness tests. Accordingly, all of the following items merit special consideration.

(a) Leakage of steam through joint between lid and chamber. Leakage may be caused by a defective gasket or by a failure to tighten the holding bolts in a satisfactory manner.

(b) Leakage of steam through a defective safety valve.

(c) Carelessness in venting air at the start of a test. The vent valve should not be closed until a strong, steady stream of steam emerges.

(d) Low line voltage.

(e) Deterioration of heating elements. The failure 
of an autoclave to heat at the specified rate, or its failure to maintain the specified test pressure, can often be corrected by replacing the heating elements.

(f) Errors in indication of pressure. In numerous instances, gages have been reset by laboratory personnel so that the indicated steam pressure would be in agreement with the temperature within the chamber as indicated by a total immersion thermometer. Such adjustments are usually in error because the thermometer well of an autoclave is designed for the use of a partial immersion thermometer. For this and other reasons, the accuracy of indication of the pressure gage should be verified periodically on a gage tester.

(g) Improper manipulation of heater controls. The initial heating rate is significantly affected by the number of bars in the chamber, and therefore it must be controlled by manipulating the heater controls in a sequence previously found to be satisfactory for the number of bars under test. Only one sequence is required if vacancies in the rack are filled with previously tested bars so that the number in the chamber will be the same for every run. Use of a voltage regulator may also prove helpful.

(h) Use of too much water in the chamber. A measured quantity of water, which is 7 to 10 percent the volume of the chamber, should be added prior to the start of each test. Use of an amount greater than 10 percent may cause an appreciable change in the heating characteristics of an autoclave. Any water remaining in the chamber at the end of a test should be removed with a siphon and the walls wiped dry with a sponge to prevent rusting.

(i) Improper adjustment of automatic pressure controls.

(j) Plugging of connecting pipes. The gradual accumulation of material in the connecting pipes may prevent the pressure regulator, the pressure gage, or the safety device from performing in a satisfactory manner. Where iron pipe and stainless steel pipe are used together in the same connecting system, electrolytic action may cause the iron pipe to plug up very rapidly.

(3) Errors in measurements due to comparator. The graduations on some dials are very difficult to read, and in some instances the physical condition of the dial face is such that accurate readings may be difficult to obtain. Dials with these deficiencies should be replaced.

\section{B. Test Procedure}

(1) Use of an incorrect amount of cement or mixing water.

(2) Allowing gage studs to shift during molding of bars.

(3) Excessive troweling of the surface of bars. Excessive troweling can be avoided if the operator uses a trowel with sharpened edges, and performs the smoothing operation by drawing the flat side of this trowel (with the leading edge slightly raised), over three-fourths of the length of the mold, in such fashion that the surface of the paste behind the trowel will be smoothed while any excess material will be "crowded" toward the end of the mold. Toward the end of the stroke, the leading edge of the trowel should be lowered to ride along the top edge of the mold, and the extra material then sliced away by the sharp edge of the trowel. The entire operation of smoothing and finishing can be completed in this manner in the course of a few passes along the mold.

(4) Allowing bars to dry after molding is completed. Bars should be put into moist storage immediately after molding is completed, and should not be disturbed until it is time to strip the mold. The procedure of smoothing the surface an hour or two after the mold has been filled does not conform with standard practice.

(5) Autoclaving bars which are less than 24 hours old.

(6) Failure to measure bars immediately after removal from moist storage.

(7) Improper cooling of bars after autoclaving. It is important that bars be cooled to room temperature prior to measurement. A cylindrical container approximately 8 in in diam and 16 in in height, equipped with a bail, makes a convenient cooling chamber. In use, this container is filled with water and placed on a hot plate at the end of the 3-hr autoclaving period. Later, when the autoclave is opened, the rack and bars as a single unit may be lifted from the autoclave by means of a suitable metal hook and immersed in the near-boiling water in the container. The container may then be transferred to a sink, and cold water introduced through a rubber tube connected to a cold water spigot. The rate of cooling may be controlled by regulation of the flow of cold water through the tube.

(8) Errors in calculations. Such errors are usually mistakes in arithmetic.

\section{Time of Setting}

Setting properties have been of interest since the very earliest days of cement testing and numerous procedures for gaging this important quality have been developed. Presently, there are two standard methods of test, namely the Vicat Time of Setting Test (ASTM Designation: C191), and the Gillmore Time of Setting Test (ASTM Designation: C266).

\subsection{Common Causes of Variations}

The two tests are similar in many respects, and therefore, there are a number of considerations which are of importance in either procedure. Some of the common causes of variations other than tlose taken into account in previous sections of this 
discussion are presented herewith.

(1) Error in the determination of the normal consistency. It is generally understood that the more mixing water used, the slower the set. The amount of mixing water may be incorrect due to an error in the determination of the normal consistency.

(2) Inadequate mixing of paste. It must be remembered that machine mixing will give unsatisfactory results if the mixer does not conform to all requirements of the applicable specifications.

(3) Regaging of paste. Regaging usually tends to make paste slower setting.

(4) Irregularities in testing. A Vicat apparatus, or a set of Gillmore needles, should be shielded from drafts of air and from direct sunlight which might cause evaporation of moisture from specimens while readings are being taken. Also, the length of time specimens are kept out of moist storage should be held to a minimum.

(5) Errors in determining time intervals. Where errors in reading times or in calculating time intervals are encountered, the use of a "militarytype" clock with a face showing the hours from 0000 to 2400 may prove helpful.

\subsection{The Vicat Time of Setting Test}

The current method of test for time of setting of hydraulic cement by the Vicat needle was developed out of equipment and procedures used in about 1818 by L. J. Vicat [20]. The evolutionary process began in Europe and had been underway there and in the United States for many years before a crude version of the present procedure was adopted as a standard test for cement in 1904.

\subsubsection{Causes of Variations}

\section{A. Apparatus}

(1) Vicat apparatus in poor condition. In general an apparatus that would not be suitable for use in normal consistency determinations would not be suitable for use in Vicat time of setting tests. Otherwise, particular attention should be given to the straightness of the needle, the diameter and the condition of its end, and the possible presence of hardened cement or rust on its sides. The condition of the needle should always be checked following a free fall through a mass of paste in a plastic state.

(2) Use of oil on Vicat ring. Use of oil on the ring to facilitate the removal of hardened paste is not particularly helpful, and introduces the possibility that the paste might be contaminated with oil during the test.

\section{B. Test Procedure}

(1) Improper procedure. The paste may not be suitable for test purposes if it has been used previously in a normal consistency determination.

(2) Failure to completely fill the Vicat ring with paste. Small holes in the paste may have a significant effect on test results.

\subsection{The Gillmore Time of Setting Test}

The use of weighted wires (needles) was originally proposed as a test for time of setting of cement by a Committee of the American Society of Civil Engineers in 1885. The wires were called "Gillmore wires" as a courtesy to General Gillmore, of the Corps of Engineers, the chairman of the committee, although they had not been proposed by him, but had been suggested by others [22]. A test based on that early method was adopted as a standard test for cement in 1916.

A set of Gillmore needles consists of an initial needle, weighing $1 / 4 \mathrm{lb}$ and equipped with a $1 / 12$-in diam cylindrical tip; and a final needle, weighing $1 \mathrm{lb}$ and equipped with a $1 / 24$-in diam cylindrical tip. Initial and final setting times are determined by the application of these needles to the flattened top of a specimen of paste (a pat) 3 in in diam at the bottom and $1 / 2$ in thick at the center. The Gillmore test is preferred by many testing agencies because it is simpler, and therefore more economical to perform, than the Vicat test. Its chief weaknesses are considered to be the failure to obtain a homogenous mass upon which to make the determination, the difficulty of applying the needles at right angles to the surface of the specimen, and the personal equation in determining when the needles cease to make an appreciable identation.

\subsubsection{Causes of Variations}

\section{A. Apparatus}

(1) Incorrect diameters of needle tips. The diameter of a needle tip may be incorrect due to errors in machining, wear, dropping, or encrustations of hardened cement.

(2) Incorrect needle weights. The weight of a needle may be incorrect due to the inadvertent loss of shot from the ball, or the addition of excess shot. New needles that do not have a shot chamber should be rejected.

(3) Failure to provide required frame for needles. The ends of needles stored in wooden blocks, or in drawers, are frequently found to be damaged. The specified frame helps to preclude such damage as well as facilitating use of the needles. Frames should be easily dismantled in order that the needles can be removed for inspection. Those not so constructed should either be corrected or discarded. New frames that cannot be dismantled should be rejected.

(4) Bent needle shafts.

\section{B. Test Procedure}

(1) Use of an incorrect amount of cement or water. Since the specified batch size makes more paste than is required to make a pat, smaller samples are sometimes mixed by hand or with a trowel. These methods usually require more mixing water than that indicated for normal consistency, and therefore the rate of hardening of the paste is 
altered. Results obtained in this manner are only approximations of the time of setting.

(2) Specimens improperly formed. This is frequently due to the failure to follow specified procedures. Among the other contributing factors are the following:

(a) Excessive troweling. If operators seem to be over-troweling specimens, an effort should be made to form pats with less than 40 troweling strokes. It is preferred that only one application of pressure be used in flattening the top of the pat.

(b) Slanting or uneven surface on top of pat. The surface of the pat should be smooth, and it should be parallel to the surface of the glass plate on which the specimen is formed. A template may be helpful in preparing specimens which have smooth, level surfaces, and which are of a uniform height. This template should not be confused with the socalled "pat mold," a device which is not suitable for use in the preparation of specimens.

(3) Variation in technique of applying needles.
The needles must always be applied at right angles to the surface of the pat.

(4) The personal equation in judging indentations. Variations in determining the point at which the pat will bear, without appreciable indentation, the Gillmore needle, may be due to inadequate lighting of the test area, and therefore the installation of special lights to ensure that surfaces of pats are adequately illuminated may prove helpful. Use of fluorescent lights or a special light box is recommended to avoid exposing pats to the "drying heat" of incandescent lights.

(5) Too frequent checking of specimens.

(6) Vibration of needles at time of application to specimen. Needles mounted on a shelf affixed to the side of a moist cabinet are affected by the shocks caused by the closing of a door of the cabinet and this disturbance may influence test results if it occurs during the application of a needle to the surface of a specimen.

\section{The Heat of Hydration Test}

A method of test for heat of hydration of portland cement (ASTM Designation: C186); based on studies conducted by L. Shartsis and E. S. Newman of the National Bureau of Standards [23], and others, was adopted in 1944. A number of changes in apparatus and methods designed to improve the precision of the determination have been made in subsequent years. The most recent of these changes were adopted in 1968.

The test is customarily listed among the physical tests of cement and therefore comes within the scope of this review. However, no comments about the related apparatus and methods are being offered because they would be of interest to only a few laboratories. For the benefit of anyone who needs such additional information, it is noted that a discussion of the test and a good bibliography can be found in "The Chemistry of Portland Cement" by R. H. Bogue [24].

\section{The False Set Test}

Development of a method of testing for premature stiffening (false set) was initiated in 1953. A method of test for determination of false set in mortar (ASTM Designation: C359), which is presently widely regarded as being useful only for research purposes, was adopted in 1955 (ASTM Designation: C451). An alternative proccdure, using cement paste and patterned closely after a method that had been part of the Federal Specifications for Hydraulic Cements for many years, was adopted in 1960. The latter was subsequently used as the basis for optional specification limits.

The paste method provides a means for evaluating the false set potential of portland cements by observation of the loss in penetration of pastes within a few minutes after mixing. An initial penetration of the plunger of a Vicat apparatus of $34 \pm 4 \mathrm{~mm}$ is used to establish that the correct amount of water has been incorporated in a machine-mixed paste. This initial penetration is recorded and a second penetration reading taken $5 \mathrm{~min}$ after completion of mixing. The percentage of penetration, as obtained by dividing the final penetration by the initial penetration and multiplying the result by 100 , indicates the extent to which false set has occurred.

\subsection{Causes of Variations}

\section{A. Apparatus}

(1) Use of unsuitable sample containers. The behavior of cements in false set tests is significantly affected by the protection afforded samples prior to testing. Use of plastic or metal containers helps to minimize exposure of samples. Use of paper or cloth sacks should be avoided.

\section{B Test Procedure}

(1) Use of an incorrect amount of cement or water. If the water requirements for all cements seem to be consistently in error, the mechanical mixer and Vicat apparatus should be checked thoroughly for conformance with the requirements of applicable specifications.

(2) Failure to observe specified time limits on test operations. Timing is a highly important factor in false set tests. Particularly so where mixing is con- 
cerned as the test tends to become more severe when the period is shortened and less likely to give an indication of false set when it is extended.

(3) Aeration of test samples. Prolonged exposure of test samples to air immediately before use may have a measurable effect on test results. Cement for a false set test should be kept in an air-tight container until the time comes for it to go into the mixing bowl.

(4) Errors in reporting test results.

\section{Air Content of Mortar}

The need for a rapid physical test whereby the air-entrainment characteristics of portland cements treated with airentraining agents could be regulated led to the adoption, in 1944, of the air content of mortar determination as a standard test for cement (ASTM Designation: C185). A number of inadequacies in the original equipment and procedures were soon recognized, and these were corrected in extensive revisions of the method in subsequent years.

The current procedure provides for the determination of the air content of machine-mixed mortar; consisting of 1 part cement, 4 parts standard sand, and the amount of water required to obtain a flow of 80 to 95 percent after 10 drops of the flow table; by comparing the weight of a 400 $\mathrm{ml}$ sample thereof to the theoretical air-free weight of a similar volume as calculated by the absolute volume method. In general, the uniformity in results is found to be better in tests of air-entraining cements than in tests of non-air-entraining cements.

\subsection{Causes of Variations}

\section{A. Apparatus}

(1) Variations in volume of $400-\mathrm{ml}$ measure. It is required that the volume of the measure be between 399 and $401 \mathrm{ml}$. In numerous instances the volumes of new containers do not conform to this requirement, and therefore, as a precaution, the volume of every new measure should be checked, and adjusted if necessary, prior to acceptance by the laboratory.

(2) Balance not suitable for test. The desired ac- curacy in test results may not be attained if the capacity of the balance is inadequate.

\section{B. Test Procedure}

(1) Use of an incorrect amount of cement, sand, or water. If water requirements for all cements seem to be consistently in error, the flow table and mechanical mixer should be thoroughly checked for conformance with the requirements of applicable specifications.

(2) Failure to place mortar gently in the measure. The technique of throwing mortar into the measure does not conform with standard practice.

(3) Failure to observe specified time limits on test operations. The desired accuracy cannot be obtained if the time limits on various test operations are disregarded.

(4) Improper handling of the 400- $\mathrm{ml}$ measure. Shaking or jolting of the measure during the filling operation must be avoided.

(5) Failure to use specified equipment in performance of test. Particular attention is invited to the advantages of using the specified spoon, spatula, tapping stick, and straightedge in the filling of the 400-ml measure.

(6) Variations in weighings. In many instances, balance weights will give more uniform results than the beam and poise with which many mix balances are now equipped.

(7) Errors in calculation. The air content of mortar is calculated from a formula given in the related test method. It is important to remember that the value for $P$ (percentage of mixing water) is always a whole number. For example, if the weight of the water is 60 percent of the weight of the cement, $P$ would be equal to 60 and not 0.60 .

\section{Strength of Mortars}

The use of mortar strength tests as a criterion of the quality of cements was recorded in the literature as early as 1772 [20]. Efforts to develop standard methods for measuring the strength of portland cement mortars began around 1848 [25] and have been carried forward by a succession of independent investigators and specification bodies since that time. Presently, both compression (ASTM Designation: C109) and tensile strength (ASTM Designation: C190) tests are included in the list of standard physical tests for portland cements.

\subsection{Common Causes of Variation}

Although there are many actual or theoretical differences between the two strength tests, the common use of mortar specimens introduces a number of considerations which would be of importance in either determination. Some of these have been covered in other parts of this review. Some are presented herewith.

(1) Nonconformance of mold design with specification requirements.

(2) Leakage of water from molds. The loss of water through the joints of a mold, or the joint between a mold and its base plate, may permit specimens to develop strengths which are higher than average. In this connection, it is important that mold base plates be of sufficient thickness to preclude bending 
during molding and handling of specimens, and that an appropriate sealant be used.

(3) Unsuitable water storage facilities. Maintenance of correct storage temperature is essential. In addition, some investigators have concluded that the $\mathrm{pH}$ of the storage water affects test results, and have recommended that a level of 7 be maintained. Others who have studied this problem have found that storage of specimens in plastic bags, along with a small amount of curing water, helps to improve the reproducibility of strength values.

(4) Improper treatment of specimens after removal from storage. It is required that all strength specimens be placed in moist air storage immediately after molding. Specimens to be tested at $24 \mathrm{hr}$ are taken directly from the moist air storage and tested at once. Specimens to be tested at later ages are transferred to water storage for additional curing. Air drying of any of these specimens just before testing can cause an increase in compressive strengths or a reduction in tensile strengths. For this reason, when several 24-hr specimens are to be tested at one time, it is recommended that they be placed in a pan immediately upon removal from moist storage, and kept covered with a moist cloth until ready for test. When two or more specimens, other than 24-hr specimens, are to be tested at one time, they should be removed from the water storage tanks, placed immediately in a pan of water, and kept there until actually tested. As immersion in water of an appreciably different temperature than the tank water just prior to testing can have a significant influence on results, it is recommended that the water in the pan be obtained from the storage tank.

(5) Failure to clean specimens prior to testing. Loose sand grains or incrustations must be removed from the bearing surfaces of specimens before they are inserted in the testing machine. If specimens seem to be excessively coated with a soapy substance, the use of a different mold lubricant should be considered.

(6) Failure to observe suitable time tolerances on testing. Every effort should be made to maintain equal intervals between the preparation and testing of strength specimens. Since it may not always be possible to do this, some tolerances on time should be observed. The following are suggested: l-day, within $1 / 2 \mathrm{hr}$; 3 -day, within $2 \mathrm{hr}$; 7 -day, within $4 \mathrm{hr}$. and 28-day, within $8 \mathrm{hr}$.

(7) Inaccuracy of testing machines. The accuracy of indication of a testing machine should be verified following its installation in a laboratory, and at least once in every two years thereafter. When the accuracy of a machine is questioned, and it is not convenient to make an immediate verification, it may prove helpful to compare results obtained with the machine in question against results obtained with machines in nearby laboratories. In these instances the comparative tests should be made on specimens from a single batch, and checks should be made in two properly equipped laboratories, rather than in just one. It may be helpful to remember that the failure to maintain a testing machine in proper operating condition is one of the common causes of errors in strength results.

(8) Failure to load test specimens at specified rate. Appropriate rates for application of loads to strength specimens have been determined by careful experimentation. Failure to use the specified rate may have a significant effect on test results, particularly in compressive strength determinations.

\subsection{The Compressive Strength Test}

The procedure whereby the strength characteristics of a cement are evaluated by the compressive strength of 2 -in mortar cubes; consisting of 1 part cement, 2.75 parts Graded Standard Sand, and the amount of water required to obtain a flow of 100 to 115 percent after 25 drops of the flow table; was adopted as a standard test for cement in 1934. It is favored by many investigators because the progressive increase in the strength of cubes, with age, parallels the increase in strength of concrete, with age, and because the agreement between laboratories using correct techniques and equipment is generally acceptable. Numerous refinements in apparatus and procedures have been made since 1934, i.e., machine mixing has replaced hand mixing and the instructions for molding of specimens have been expanded, with the result that the number of laboratories reporting unreasonable compressive strength values has been substantially reduced.

\subsubsection{Causes of Variations}

\section{A. Apparatus}

(1) Nonplaneness of interior faces of molds. Differences in strength ranging from 3 percent at 1 day to 8 percent at 28 days were found on one occasion where 2 -in mortar cubes were tested between convex blocks having a mid-ordinate of 0.004 in [26]. These findings are believed to be indicative of the influence nonplaneness of mold faces may have on test results.

(2) Failure to keep corners of molds clean. The accumulation of hardened cement in the corners of the pockets in a cube mold reduces the overall size of test specimens, and thereby causes reductions in compressive strengths. Prompt cleaning of the molds after stripping will help to avoid this difficulty, and normally most of the residue can be removed with a damp cloth if cleaning is undertaken before the material has had an opportunity to harden in air.

(3) Excessive use of oil on molds.

(4) Inadequate sealing of molds. Operators frequently fail to follow the instructions for sealing of cube molds. In numerous instances, the departure is attributed to difficulty in applying the specified sealing material. One effective technique is to melt the material in a conventional oil can with a "cutdown" spout. and to apply the liquid thus obtained to the mold. as one might apply oil. while holding the hot can in a hand protected by an asbestos glove. 
This procedure will work with either the paraffinrosin mixture mentioned in ASTM Method C109 or the microcrystalline wax mentioned in Federal Test Method 2001.1.

(5) Problems with spherical blocks on compression machines. Common problems include the following:

(a) Block frozen in place and therefore unable to adjust to specimen.

(b) Improper design of block.

(c) Damage to spherical block that prevents normal movement.

(d) Use of lubricant other than light oil on surface of sphere.

(e) Contact between sphere and its seat occurring only at top of sphere.

(6) Nonplaneness of faces of compression machine bearing blocks. Reductions in compressive strength as great as 25 percent are known to have occurred where blocks with very uneven bearing surfaces were being used. All blocks tend to lose their planeness with usage, and the change may occur rapidly if the faces have not been properly hardened. Planeness can be checked with a flashlight and a toolmaker's straightedge. If the planeness is within 0.001 in as required, very little, if any, light will show between the straightedge and the surface of the block when the flashlight is held behind the straightedge. If a more conclusive check is desired, a piece of cellophane from a cigarette pack can be used beneath the straightedge as a feeler gage.

(7) Inadequacies in design of testing machine. Dials on testing machines used in determining the compressive strengths of mortars should conform to the requirements for dials set forth in ASTM Designation C39.

(8) Inadequate maintenance of compression testing machine. Every laboratory should be provided with maintenance literature for the compression machine it uses, and all special maintenance equipment should be available, i.e., the special wrench and oil gun needed for machines equipped with a fluid support. The indicating hands should be checked periodically for freedom of movement, with particular attention being given to maximum hands. The level of oil in all oil reservoirs should be checked frequently. In the event of mechanical failure, the services of a competent repairman should be obtained promptly.

\section{B. Test Procedure}

(1) Use of an incorrect amount of cement, sand, or water. If the water requirements for all cements seem to be consistently in error, the flow table and mechanical mixer should be checked thoroughly for conformance with the requirements of applicable specifications.

(2) Mixing of mortars by hand. The mixing of , mortars by hand, rather than with the mechanical mixer as specified, will usually produce lower test results.

(3) Variations in tamping pressures. Nonuniformity in the tamping pressures used in compacting mortar in the mold pockets is a variable in compres- sive strength determinations.

(4) Improper positioning of specimens on compression machine bearing blocks. It is important that cubes be centered carefully on the bearing blocks of the testing machine. The use of a special centering template may be helpful.

(5) Failure to zero compression machine properly at start of test.

(6) Errors in reporting test results. A confusing error, particularly where low strengths are concerned, is the failure to divide the load in pounds by four to obtain pounds per square inch.

\subsection{The Tensile Strength Test}

The procedure whereby the strength characteristics of a cement are evaluated by the tensile strength of 1 -in thick, figure- 8 mortar specimens (briquets); consisting of 1 part cement, 3 parts Standard Sand, and the amount of water indicated by the normal consistency determination; was introduced about 1880 [25], and was adopted as a standard test for cement in 1904. The test has been favored by many investigators because it is simple, and therefore economical to perform. The retrogression of strength with age, which is sometimes encountered, is frequently mentioned as a dis. advantage.

\subsubsection{Causes of Variations}

\section{A. Apparatus}

(1) Unsatisfactory work gloves. Rubber gloves must be pliable and snug-fitting so that they will not prevent uniform and vigorous movement of the fingers throughout the mixing period.

(2) Use of worn test apparatus. When strength values seem to be consistently in error, all apparatus should be carefully checked for conformance with the requirements of applicable specifications. A particular problem in recent years has been the low strength of specimens produced in molds which have worn so thin as to no longer comply with minimum thickness requirements. Another problem has been the leakage of water from molds which are worn in such fashion that the halves no longer meet at all points.

(3) Variations in mold design. The molds presently in use vary from the single-pocket to the sixpocket type, and fabrication techniques tend to vary with the type of mold. It would be advantageous for all laboratories to use the customary threepocket type.

(4) Inadequate maintenance of testing machine. From time to time, grips are observed wherein the rollers are no longer free to turn. This and other important maintenance problems are discussed in detail in existing publications [21].

\section{B. Test Procedure}

(1) Use of an incorrect amount of cement, sand, or water. Consistent errors in the amount of mixing 
water used may indicate an error in the normal consistency determination, or an error in calculating the amount of water from the normal consistency. In this latter calculation, the given percentage of water is expressed in terms of the weight of cement and sand, and not in terms of the weight of the cement alone.

(2) Use of mixing equipment coated with oil or other contaminants.

(3) Use of gloves, trowels, or mixing slabs that have not been allowed to dry.

(4) Loss of mixing water due to evaporation. Use of too large an area on the mixing slab during hand mixing promotes evaporation of water.

(5) Variations in techniques for filling molds. Where two or more molds are being filled from the same batch, each phase of the fabrication process should be completed on each mold before the next phase is started, i.e., compaction of the mortar into each pocket in each mold should be completed before the heaping and smoothing operation is started. The mortar in each pocket should be flush with the top of the mold when smoothing is completed.

(6) Improper compaction of mortar in the mold pockets. It is recommended that the thumb pressures be applied in groups of two per briquet on each of six trips along the mold. Care should be taken that the thumb pressures are applied entirely to the surface of the mortar, and not to the surface of the mold. The specified thumb pressure of between 15 and $20 \mathrm{lb}$ may be measured by molding the briquets on a platform scale or on other suitable apparatus that will indicate the pressure exerted.

(7) Variations in techniques of finishing specimens. In standard practice the excess material is removed from the molds with a smoothing motion rather than with a sawing motion. Mastery of the smoothing operation requires a certain amount of practice, and therefore many laboratories permit inexperienced operators to use the simpler sawing procedure while learning the test. The prescribed smoothing technique should be adopted at the end of the apprenticeship period.

(8) Failure to remove all sand grains from face of mold. Sand grains between the mold and its base plate promote the loss of mixing water from finished specimens as well as an increase in thickness. Either of these conditions is capable of causing an apparent increase in strength.

\section{Closure}

This discussion of causes of variation in physical tests of portland cement has been written in such fashion that it constitutes a master check list with explanatory comments. If further assistance is needed, complementary check sheets can be obtained from the Cement and Concrete Reference
Laboratory, National Bureau of Standards, Washington, D.C. 20234.

The author acknowledges the assistance and advice received from his associates in the Cement and Concrete Reference Laboratory.

\section{References}

[1] Youden, W. J., Statistical aspects of the cement testing program, ASTM Proc. 59, 1120 (1959).

Crandall, J. R., and Blaine, R. L., Statistical evaluation of interlaboratory cement tests, Ibid., p. 1129.

[2] Bean, L., and Hackney, E. J., A study of some operations involved in cement analysis, ASTM Bull. 197, 44 (Apr. 1954).

[3] Information concerning pyrometric cones may be obtained from The Edward Orton Jr., Ceramic Foundation, 1445 Summit St., Columbus 1, Ohio.

[4] Private communication.

[5] Roberts, H. S., Phys. Rev. 23, 386 (1924).

[6] Hillebrand, W. F., Lundell, G. E. F., Bright, H. A., and Hoffman, J. I., Applied Inorganic Analysis, pp. 32-33, 46-51, 503. (Published by John Wiley \& Sons, Inc., New York, N.Y., 2d ed., 1953.)

[7] Book of ASTM Standards, Part 9, C114-67 (1968).

[8] Fed. Test Method Std. No. 158, Sept. 1960: Cements hydraulic: sampling, inspection, and testing; method 1001 , par. 4.2.

[9] Kolthoff, I. M., and Sandell, E. B., Textbook of Quantitative Inorganic Analysis. p. 391 (Published by the Macmillan Co., New York, N.Y., 3rd ed., 1952).

[10] Hoffman, J. I., and Lundell, G. E. F., The precipitation and ignition of magnesium ammonium phosphate, BS J. Res. 5 , 279-93 (1930), RP200.

[11] Berman, H. A., An improved 8-hydroxyquinoline method for the determination of magnesium oxide in portland cement, ASTM Bull., 237, 53 (Apr. 1959).

[12] Rudy, R. B., Determination of sulfuric anhydride in portland cement by means of the Wagner Turbidimeter, J. Res. NBS 16, 555 No. 6 (June 1936), RP893.

[13] Bright, H. A., Determination of sulphur occurring as sulphide in portland cement. J. Res. NBS 18, 137 No. 2 (Feb. 1937), RP968.

[14] Chaiken, B.. Determination of ignition loss in portland blastfurnace slag cements, ASTM Bull., No. 238, p. 53 (May 1959).

[15] Diamond, J. J., and Bean, L., Improvements in flame photometric determination of sodium in portland cement, Anal. Chem. 25, 1825 (Dec. 1953).

[16] Halstead, W. J., and Chaiken, B., Insoluble residue determination in portland and portland-slag cements, ASTM Bull. No. 229, pp. 60-65 (Apr. 1958).

[17] DeFore, M. R., and Corah, H. J., A test method for airentrainment of standard Ottawa sand, ASTM Bull. No. 248 (Sept. 1960).

[18] Wagner, L. A., A rapid method for the determination of the specific surface of portland cement, ASTM Proc. 33, 553 pt. II (1933).

[19] Blaine, R. L., A simplified air permeability fineness apparatus, ASTM Bull. No. 123, p. 51 (Aug. 1943).

[20] Gonnerman, H. F., Development of cement performance tests and requirements, P. C. A. Research Bull. No. 93 (Mar. 1958). 
[21] Book of ASTM Standards, Part 9, Appendix I. Manual of cement testing.

[22] Data considered by Committee C-1 of the American Society for Testing Materials in Preparing the Standard Specifications and Tests for Portland Cement (Serial Designation C 9-17).

[23] Shartsis, L., and Newman, E. S., A study of the heat of solution procedure for determining the heat of hydration of portland cement, ASTM Proc. 43, p. 905 (1943).

[24] Bogue, R. H., The Chemistry of Portland Cement, p. 606 (Reinhold Publishing Corp., New York, N.Y.).

[25] Swayze, M. A., The testing of cements for inlierent strength, ASTM Bull. No. 209 (Oct. 1955).

[26] Dwyer, J. R., Effect of departure from planeness of bearing surfaces on compressive strength of 2 -in. mortar cubes, ASTM Proc. 36, 351 pt. II (1936). 


\section{Announcement of New Publications in Building Science Series}

Superintendent of Documents,

Government Printing Office,

Washington, D.C. 20402

Dear Sir:

Please add my name to the announcement list of new publications to be issued in the series: National Bureau of Standards Building Science Series.

Name

Company

Address

City

State

Zip Code

(Notification key $\mathrm{N}-339$ ) 


